\title{
PARTICIPATION OF THE PENNSYLVANIA STATE UNIVERSITY IN THE MAP3S PRECIPITATION CHEMISTRY NETWORK
}

\author{
Final Report
}

Dennis Lamb and Rosa G. de Pena

Meteorology Department

The Pennsylvania State University

University Park, PA 16802

April 1991

Prepared for

THE U.S. DEPARTMENT OF ENERGY

GRANT NO. DE-FG02-85ER60294 


\section{NOTICE}

This report was prepared as an account of work sponsored by the United States Government. Neither the United States nor the Department of Energy, nor any of their employees, nor any of their contractors, subcontractors, or their employees, makes any warranty, express or implied, or assumes any legal liability or responsibility for the accuracy, completeness, or usefulness of any information, apparatus, product or process disclosed or represents that its use would not infringe privately-owned rights. 


\section{ABSTRACT}

The Meteorology Department of the Pennsylvania State University collected precipitation in central Pennsylvania for more than 14 years on behalf of the Multistate Atmospheric Power Production Pollution Study (MAP3S). The MAP3S protocol, based on the sampling of precipitation from individual meteorological events over a long period of time, has allowed both for the development of a chemical climatology of precipitation in the eastern region of the United States and for a vastly improved understanding of the atmospheric processes responsible for wet acidic deposition.

The precipitation chemistry data from the Penn State MAP3S site provide evidence of links to the anthropogenic emissions of sulfur dioxide and oxidant precursors. There is now little doubt that the free acidity in the precipitation of the region is due to the presence of unneutralized sulfate in the aqueous phase In the absence of significant sources of this sulfur species and in view of supplemental enrichment studies, it is concluded that the sulfate enters cloud and rain water primarily through the aqueous-phase oxidation of sulfur dioxide emitted into the air within the geographical region of deposition. Within the source region the local abundances of sulfur dioxide often exceed those of the oxidants, so the depositions of sulfate and free acidity tend to be modulated by the availability of the strong oxidants. As a consequence, the deposition of sulfate exhibits a very strong seasonal dependence and little response to changes in the emissions of sulfur dioxide. 


\section{CONTENTS}

\section{Page}

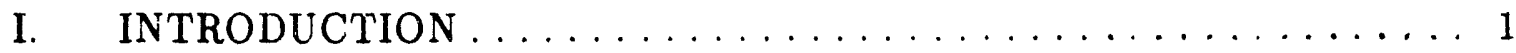

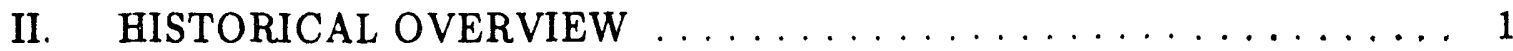

III. OPERATIONS $\ldots \ldots \ldots \ldots \ldots \ldots \ldots \ldots \ldots \ldots$

IV. RESEARCH ACTIVITIES $\ldots \ldots \ldots \ldots \ldots \ldots \ldots \ldots \ldots$

1. Intercomparisons $\ldots \ldots \ldots \ldots \ldots \ldots \ldots \ldots$

2. The Data Record ..................... 20

3. Trajectory Analyses $\ldots \ldots \ldots \ldots \ldots \ldots \ldots \ldots \ldots \ldots$

4. Sulfate Scavenging ................... 33

V. CONCLUSIONS $\ldots \ldots \ldots \ldots \ldots \ldots \ldots \ldots \ldots \ldots \ldots$

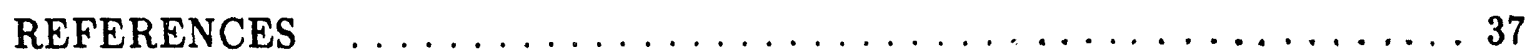

APPENDICES 


\section{LIST OF FIGURES}

Fig. 1. Locations of the MAP3S and NADP/NTN sites in the U.S.

Fig. 2. Plan view of the site as arranged presently.

Fig. 3. Detailed layout of the northwest quadrant of the site.

Fig. 4. Scattergram of sample depths measured in the MAP3S duplicated collectors.

Fig. 5. Scattergram of $\mathrm{pH}$ values measured in the MAP3S duplicated collectors.

Fig. 6. Time series of the differences in the $\mathrm{pH}$ values of the MAP3S duplicated data.

Fig. 7. Scattergrams of the MAP3S duplicated $\mathrm{pH}$ values subdivided to reflect the time of faulty equipment (Period 1) and the time after repair (Period 2).

Fig. 8. Scattergram of hydronium concentration.

Fig. 9. Scattergram of sulfate concentration.

Fig. 10. Annual deposition of major ions and precipitation during MAP3S.

Fig. 11. The relationship between the concentrations of the hydronium and sulfate ions during selected events between August 1985 and January 1987.

Fig. 12. The relative composition of inorganic ions in MAP3S precipitation expressed as mole percentages. RES refers to the residual components needed to balance the ionic charges.

Fig. 13. The relative composition of ions in aerosol samples expressed as mole percentages. RES refers to the residual components needed to balance the ionic charges.

Fig. 14. Annual deposition of hydronium subdivided into seasons.

Fig. 15. Annual deposition of sulfate subdivided into seasons.

Fig. 16. Monthly averaged deposition and precipitation data.

Fig. 17. Deviations of monthly sulfate deposition from the monthly means.

Fig. 18. Back trajectory of air arriving at the Penn State site preceding a high-deposition event.

Fig. 19. Back trajectory of air arriving at the Penn State site preceding a low-deposition event.

Fig. 20. Schematic representation of a synoptic-scale weather system. 


\section{INTRODUCTION}

For a period of more than 14 years the Meteorology Department of the Pennsylvania State University participated in the Precipitation Chemistry Network of the Multistate Atmospheric Power Production Pollution Study ("MAP3S"; MacCracken, 1978; MAP3S/RAINE, 1982; Dana and Easter, 1987). The program, focused largely on the monitoring of the wet deposition fluxes of secondary pollutants derived from the combustion of fossil fuels during power generation, has provided an important record of the chemical climatology of precipitation in the northeastern region of the United States. Because the MAP3S protocol for precipitation collection called for the resolution of individual meteorological events, the data record has also proven valuable for improving our understandings of the atmospheric processes responsible for the transport and transformations of energy-related pollutants. Now that the Department of Energy (DOE) has lost its commitment to this historical endeavor, it is appropriate to summarize the operational and research activities of the Penn State atmospheric research site over the lifetime of the MAP3S program.

\section{HISTORICAL OVERVIEW}

The Penn State atmospheric research station was established in September 1976 initially to collect precipitation for chemical analysis on behalf of the MAP3S Precipitation Chemistry Network (MacCracken, 1978). It continued to function in this capacity at least into early 1991, as well as to host a variety of other atmospheric sampling programs. Sampling of precipitation on behalf of the NADP/NTN began at the site in mid-1983 and continues to the present time. The geographic relationship of the Penn State site (40047'18" north latitude and 77058'47" west longitude) to each of these major networks is depicted in Fig. 1. 


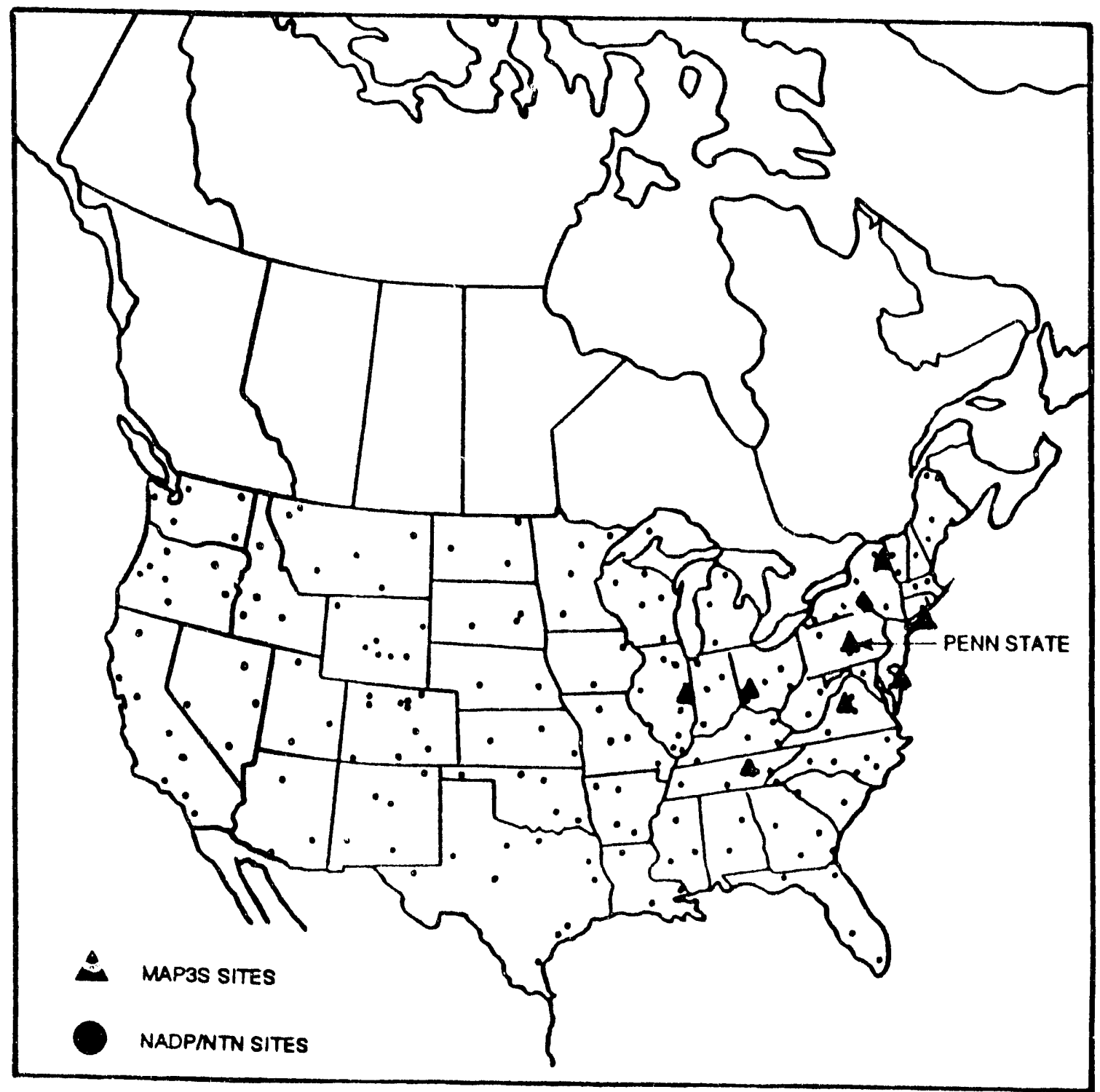

Figure 1. Locations of the MAP3S and NADP/NTN sites in the U.S. 
A particularly important attribute of the Penn State site is the rural setting of the central Pennsylvania region. As surveyed by Bowersox (1980), all significant point sources of pollution, with the exception of the town of State College (permanent population about $40,000)$, are in excess of $40 \mathrm{~km}$ from the sampling site. The major pollution sources along the prevailing upwind direction are at least $100 \mathrm{~km}$ away. The influence of State College on the precipitation chemistry data is minimal because its location is upwind of the site by about $6 \mathrm{~km}$. The Penn State site has been given a rating of $2 \mathrm{~A}$, meaning that it is potentially regionally representative (Sweeney and Olsen, 1987).

The site itself is a leveled, clear-cut square, approximately $180 \mathrm{~m}$ on a side, located on a large tract of Pennsylvania State Game Lands that is forested with oak, aspen, and pine. This forested area lies at an altitude of $400 \mathrm{~m}$ above sea level approximately in the middle of a broad valley defined by two ridges (tops about $600 \mathrm{~m}$ ) of the Appalachian Mountains. The surrounding trees, about $20 \mathrm{~m}$ high along the north side $0 i^{\circ}$ the clearing and $15 \mathrm{~m}$ elsewhere, afford a natural barrier against the full force of the winds and and act as a filter against dust that may be dispersed into the air by vehicles traveling along an unpaved stretch of road that bisects the forest and comes within about $200 \mathrm{~m}$ of the clearing. Access to the site is gained from this unpaved road by a paved road about $600 \mathrm{~m}$ long, use of which is restricted to personnel servicing the site. The MAP3S and NADP/NTN sampling equipment are located about $10 \mathrm{~m}$ apart from each other in the southwest quadrant of the clearing, well away (about $15 \mathrm{~m}$ ) from the drip lines of wires comprising a large radio antenna grid located in the clearing.

The original configuration of the Penn State site was established by Van Bowersox and Rosa de Pena. The early equipment consisted of a wet-dry collector from the Health and Safety Laboratory (HASL) and a wet-only collector from Battelle Pacific Northwest Laboratories. About a year after the start of the program a second Battelle collector was added, one which enabled the sample to be kept near $4{ }^{\circ} \mathrm{C}$ for the purpose of preserving sample integrity until retrieval from the field. These collectors were supplemented with a 
tipping-bucket rain gage with thermostatted heating and Alter windshield, as well as with a Lundgren impactor to determine the distribution of aerosol chemical composition with particle size.

Initial comparisons of the chemical data derived from the precipitation collectors were designed to test ideas related to the stability of the S(IV) compounds dissolved in the rainwater. For that purpose the results from the Battelle collector were compared with those from the HASL, later the AeroChemetrics collector. Subsequently, other collectors were added to the site for comparison purposes, such as the Sangamo collector from Canada. From December 1979 to April 1980, and again from September 1982 until 1984, an ERNI 721 automatic wet deposition collector was used for sub-event sampling. Weekly precipitation samples were collected under the NADP protocol with a second AeroChem collector beginning in 1981. Finally, during the years from 1985 to 1987 three MISCO collectors were colocated at the site and compared with the MAP $3 S$ AeroChem collector in parallel with the routine monitoring operations.

Beginning in the fall of 1987 the Penn State site underwent substantial changes, though without sacrifice to the MAP3S program. These changes represented an expan-ion of operational and research capabilities to meet the needs for obtaining data suitable for validation of various regional acid deposition models, such as RADM (Chang et al., 1987). Figures 2 and 3 indicate this configuration of equipment. Most notable, perhaps, is the array of up to eight new collectors that were colocated within the rectangular dashed line in the upper left quadrant of Fig. 2. The expanded view of Fig. 3 shows the locations of the van $(P)$ for housing the various colocated gas and aerosol sampling equipment and the array of filter sampling towers (F). Table 1 summarizes the $;$ rograms included in the site operations. These operations and research efforts at the site furthered a long tradition of conducting high-quality intercomparison measurements for numerous agencies involved in the environmental sciences. However, emphasis is now placed less on the hardware used for the sampling operation and more on the comparison of protocols and on the quantitative 


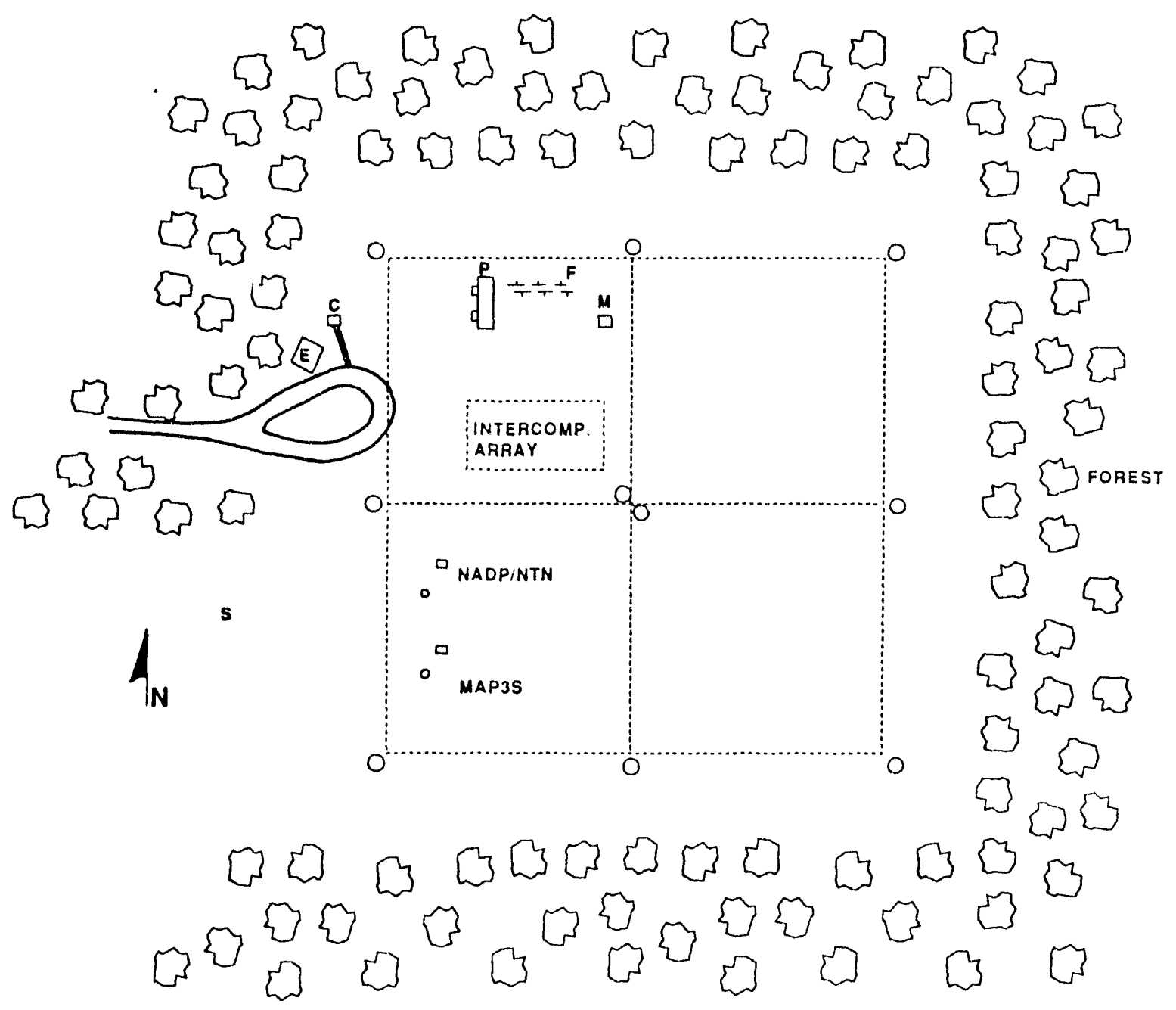

Figure 2. Plan view of the site as arranged presently. 


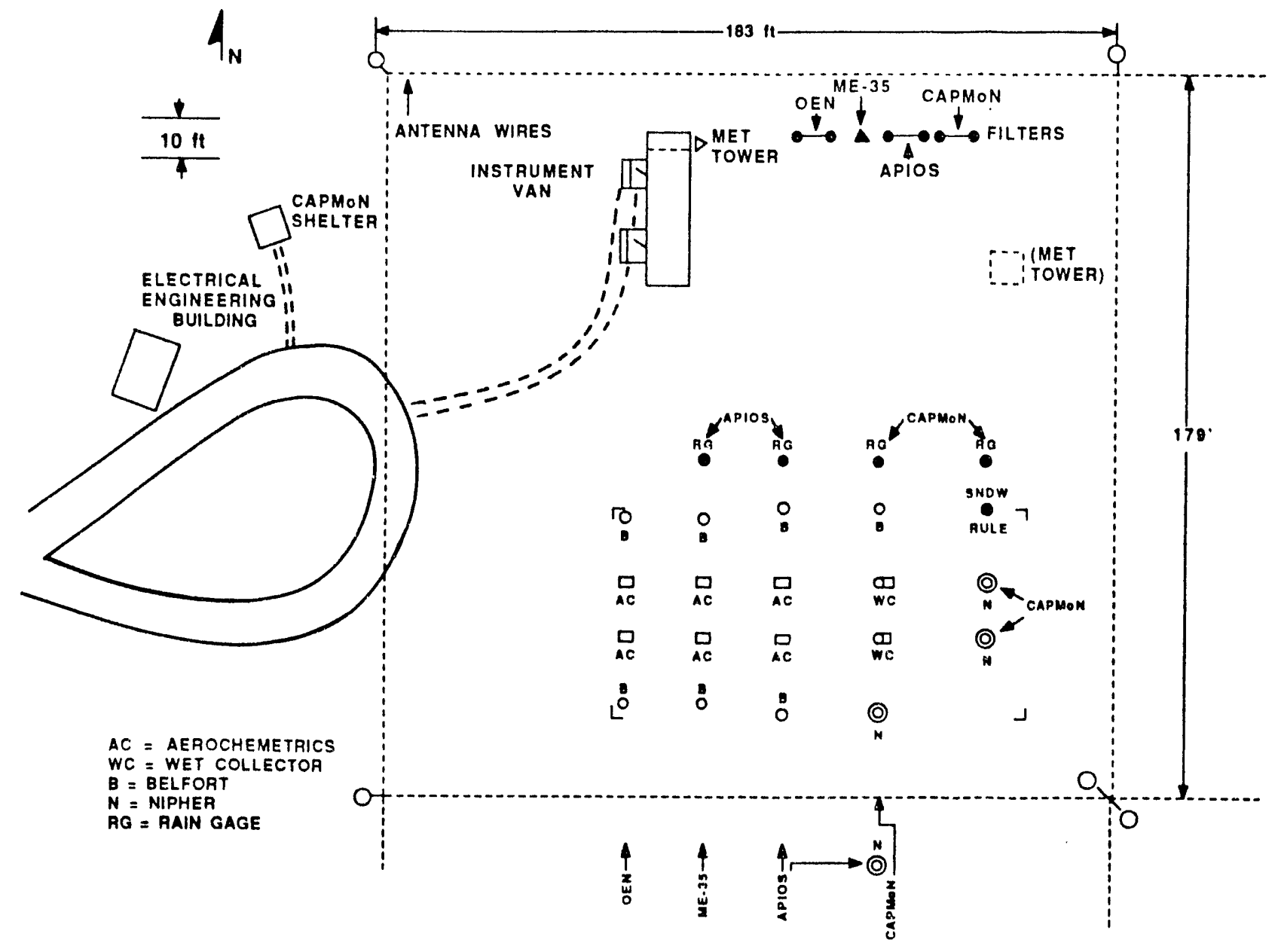

Figure 3. Detailed layout of the northwest quadrant of the site. 
Table 1. Sampling Programs using the Penn State Scotia Research Site

\begin{tabular}{|c|c|c|c|}
\hline Program & $\frac{\text { Varlable }}{\text { Class }}$ & $\begin{array}{l}\text { Sampling } \\
\text { Intervals }\end{array}$ & Sponsoring Agency \\
\hline MAP3S & Precipitation & Daily & DOE \\
\hline NADP/NTN & Precipitation & Weekly & DOC-NOAA ARL \\
\hline OEN & $\begin{array}{l}\text { Preclpitation } \\
\text { Alr }\end{array}$ & $\begin{array}{l}\text { Dally } \\
\text { Dally \& Continuous }\end{array}$ & EPRI/ERT \\
\hline ME35 & $\begin{array}{l}\text { Precipitation } \\
\text { Air }\end{array}$ & $\begin{array}{l}\text { Dally } \\
\text { Daily \& Continuous }\end{array}$ & EPA/ERT \\
\hline APIOS & $\begin{array}{l}\text { Precipitation } \\
\text { Air }\end{array}$ & $\begin{array}{l}\text { Dally } \\
\text { Daily \& Continuous }\end{array}$ & Ontario MOE \\
\hline CAPMON & $\begin{array}{l}\text { Precipitation } \\
\text { Air }\end{array}$ & $\begin{array}{l}\text { Dally } \\
\text { Dally \& Continuous }\end{array}$ & Canadian AES \\
\hline (Spectal) & Alr & Daily \& Continuous & DOC-NOAA ERL \\
\hline
\end{tabular}

Acronyms :

$\begin{array}{ll}\text { MAP3S: } & \text { Multistate Atmospheric Power Production Pollution Study } \\ \text { NADP: } & \text { National Atmospheric Deposition Program } \\ \text { NTN: } & \text { National Trends Network } \\ \text { OEN: } & \text { Operational Evaluation Network } \\ \text { ME35: Model Evaluation (involving } 35 \text { stations) } \\ \text { APIOS: Acid Precipitation in Ontario Study } \\ \text { CAPMoN: Canadian Air Precipitation Monitoring Network } \\ \text { DOE: } & \text { Department of Energy } \\ \text { DOC: } & \text { Department of Commerce } \\ \text { NOAA: } & \text { National Oceanic and Atmospheric Adminlstration } \\ \text { ARL: } & \text { Alr Resources Laboratory } \\ \text { ERL: } & \text { Environmental Research Laboratories } \\ \text { EPRI: } & \text { Electric Power Research Institute } \\ \text { EPA: } & \text { Environmental Protection Agency } \\ \text { ERT: } & \text { ERT, Inc. } \\ \text { MOE: } & \text { Ministry of the Environment } \\ \text { AES: } & \text { Atmospheric Environment Service }\end{array}$ 
determination of measurement precision. Throughout the history of the DOE program, the MAP3S collection systems remained approximately as shown in Fig. 2.

\section{OPERATIONS}

Details of the MAP3S protocol have been provided in MAP3S/RAINE (1982) and will not be repeated here. Precipitation was sampled on the wet-only side of an Aerochem Metrics Wet-Dry Collector, a device identical to the wet-dry collector used by NADP/NTN. In both cases, precipitation could be sampled with minimal influence from dry deposition. Rainfall amount was measured with a Belfort recording gage. The fundamental difference between the two protocols is the sampling period.

From the onset of the MAP3S Program in 1976, data were to resolve individual meteorological events (MacCracken, 1978), although no formal definition of an "event" has been made. Often, a metenrological precipitation event is a specific frontal passage or convective storm. Whereas the minimum sampling period is well defined at 24 hours, the period may last several days until a distinct change in the weather pattern appears. Operator judgment thus becomes an implicit element of the data set, but at least the measured composition of the precipitation has some causal relationship to meteorological phenomena.

At the Penn State site all MAP3S precipitation samples were collected under this "event" concept until 31 January 1988. Beginning 1 February 1988 the sampling interval was specified to be 24 hours, beginning and ending at 08:00 AM Eastern Time. This shift to a daily sampling protocol was made in part to remove the subjective element of sampling by events and to improve the temporal resolution of the data. All anaiyses thus contains both "event" and "daily" MAP3S data, although the term "event" may be used generically to distinguish the MAP3S data from the "weekly" data derived from the NADP/NTN protocol. On 1 January 1989, another Aerochem Metrics collector was 
deployed at the site, about $5 \mathrm{~m}$ from the "main" MAP3S collector, in order to obtain a "duplicate" set of MAP3S data and so estimate the precision of the measurements made under the MAP3S protocol.

All MAP3S samples, whether "event" or "daily" or whether from the main collector or from the duplicate collector, experienced the same handling and analysis procedures. The precipitation samples were first weighed in their buckets and then "field" analyzed for $\mathrm{pH}$ and electrical conductivity. A separate aliquot was then drawn and spiked with TCM solution in order to fix the S(IV) content of the precipitation. The samples were shipped in separate polyethylene bottles to the Pacific Northwest Laboratory of Battelle in Richland, Washington, for complete chemical analysis. After being subjected to w $1 ?$ tefined quality assurance procedures (Dana and Barchet, 1989), the data were archived is the ADS data base (Watson and Olsen, 1984).

Precipitation chemistry data derived from samples gathered at the Penn State site were routinely added to a data base residing in an IBM AT-class computer in the laboratory. A variety of applications programs have made it relatively easy for personnel to access any of the data and to work with them in a number of different ways. In addition to the routine precipitation collections, special measurements of air and precipitation chemistry have been made on occasion for research purposes.

\section{RESEARCH ACTIVITIES}

\section{Intercomparisons}

One of the earliest and continuing research themes addressed in the Penn State program has been the intercomparison of collectors and sampling protocols. At the onset, comparisons of the HASL, early Battelle, AeroChem, and Sangamo collectors helped to identify problem areas and to establish good operating procedures for event sampling of precipitation (de Pena et al., 1980). When the weekly sampling protocol of NADP began, 
the effect of the sampling interval was investigated by averaging the event data from MAP3S over the corresponding weekly intervals of the NADP data (de Pena et al., 1985). A more recent comparison between these two data setc has been described by Lamb and Comrie (1991; Appendix I). Some aspects of this between-network intercomparison are described below, after a brief description of the MAP3S precision measurements has been given.

MAPSS Precision. The data obtained from the two colocated MAP3S wet-only collectors provide, for the first time in the MAP3S network, a quantification of measurement precision, as well as valuable diagnostic information. A more detailed description is provided in Appendix I. Complete chemical analyses of the samples are not availahle as of this writing, so only field data are presented here. As shown in Fig. 4, the daily volumes of the samples taken from the colocated (new) collector correlate extremely well with those taken from the main (on-going) collector.

Despite the good agreement between the volumes of precipitation gathered by the MAP3S colocated collectors, the values of $\mathrm{pH}$ measured in the same samples did not show very good agreement when plotted the same way (Fig. 5). Nevertheless, inspection of the pH data in Fig. 5 reveals that many of the data points lie close to the 1:1 line. When the differences between the two data sets are plotted against sample number (a surrogate measure of time) from the onset of the comparison, as shown in Fig. 6, a clear change in character is evident part way through the data set. Partly in response to the discrepancies in $\mathrm{pH}$ readings noted by the operator on any given day, a faulty (leaky) gasket seal was found on the lid of the new collector and replaced on 6 July 1989 (sample number 89). The erratic nature of the early data is likely to be due to contamination of the duplicate samples while sitting in the collection bucket at the site.

In view of the physical cause to the discrepancies in the duplicated $\mathrm{pH}$ measurements, the data set has been broken into two subsets at the point at which the lid gasket was replaced. Figure 7 separately shows the scatter plots for the first period (4 January 1989 to 


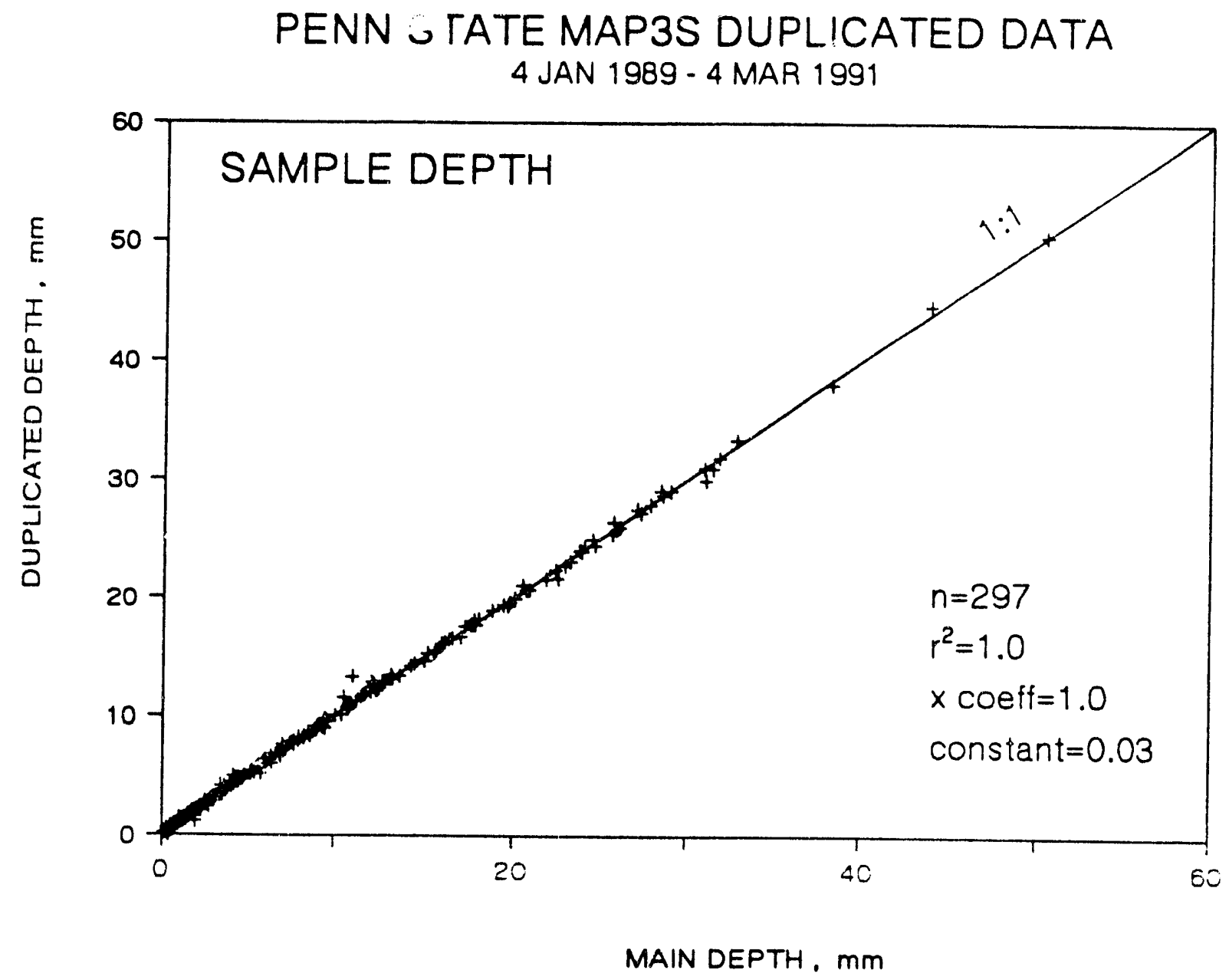

Figure 4. Scattergram of sample depths measured in the MAP3S duplicated collectors. 


\section{PENN STATE MAP3S DUPLICATED DATA}

4 JAN 1989 - 4 MAR 1991

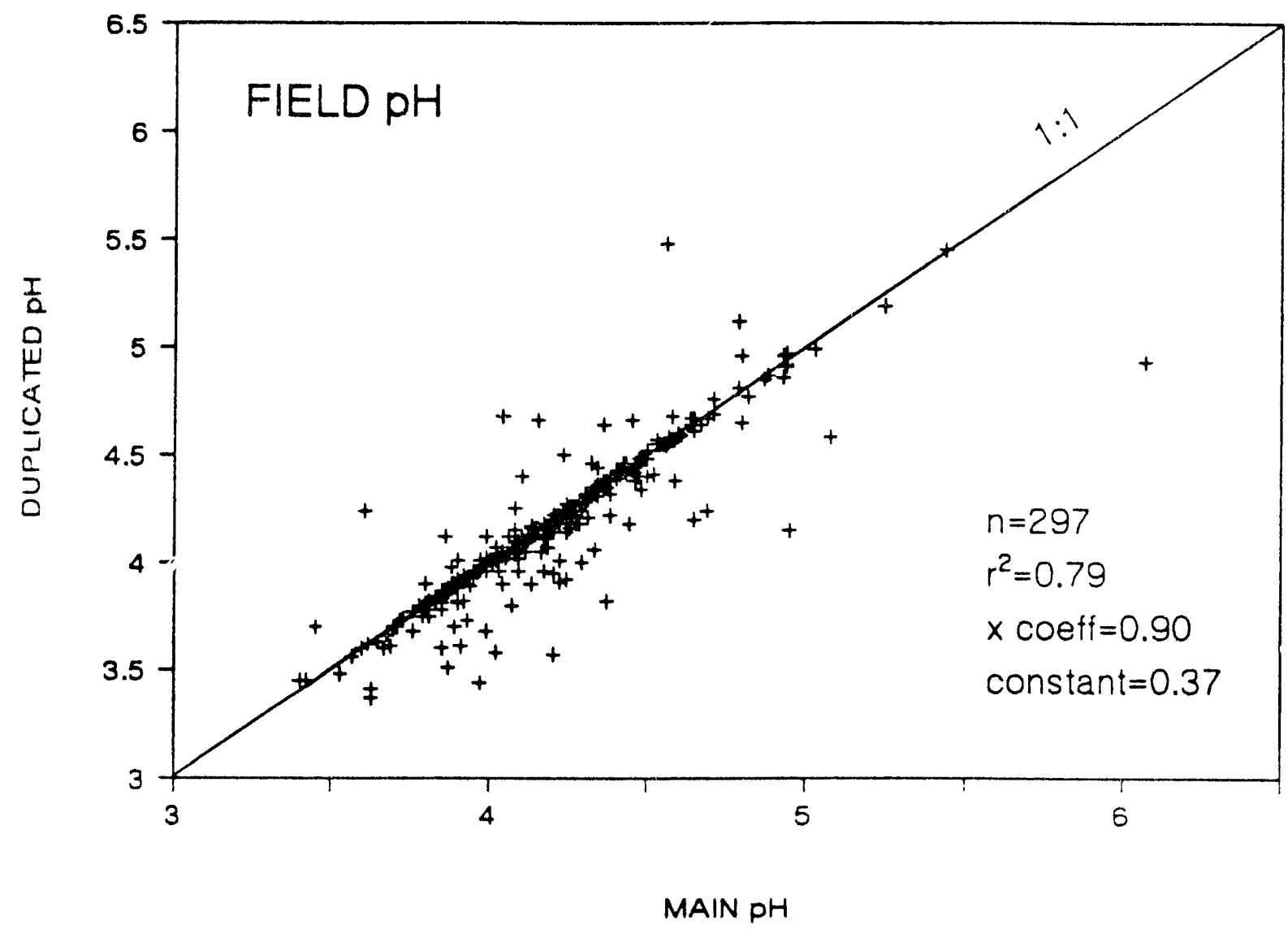

Figure 5. Scattergram of $\mathrm{pH}$ values measured in the MAP3S duplicated collectors. 


\section{PENN STATE MAP3S DUPLICATED DATA}

4 JAN 1989 - 4 MAR 1991

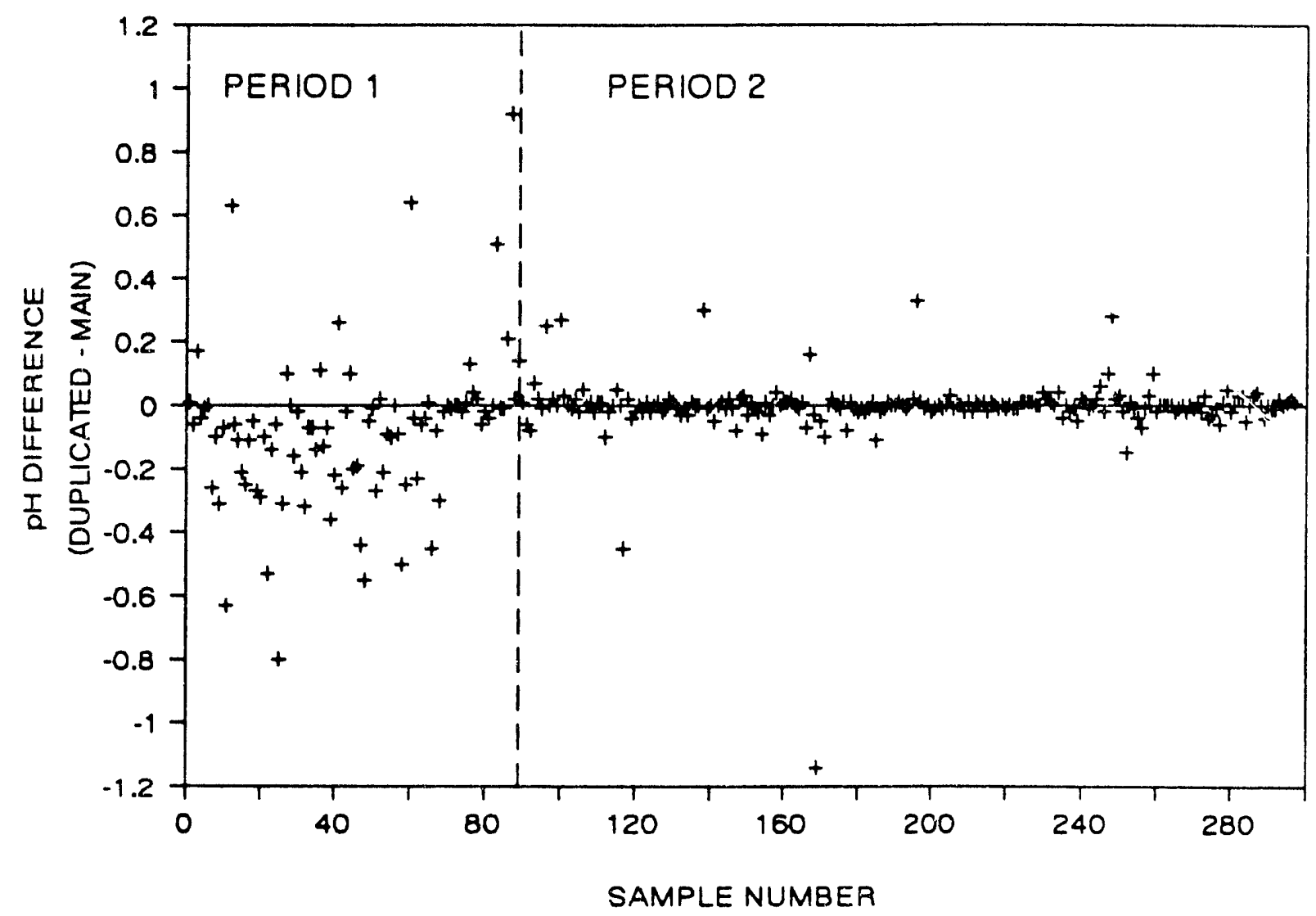

Figure 6. Time series of the differences in the $\mathrm{pH}$ values of the MAP3S duplicated data. 


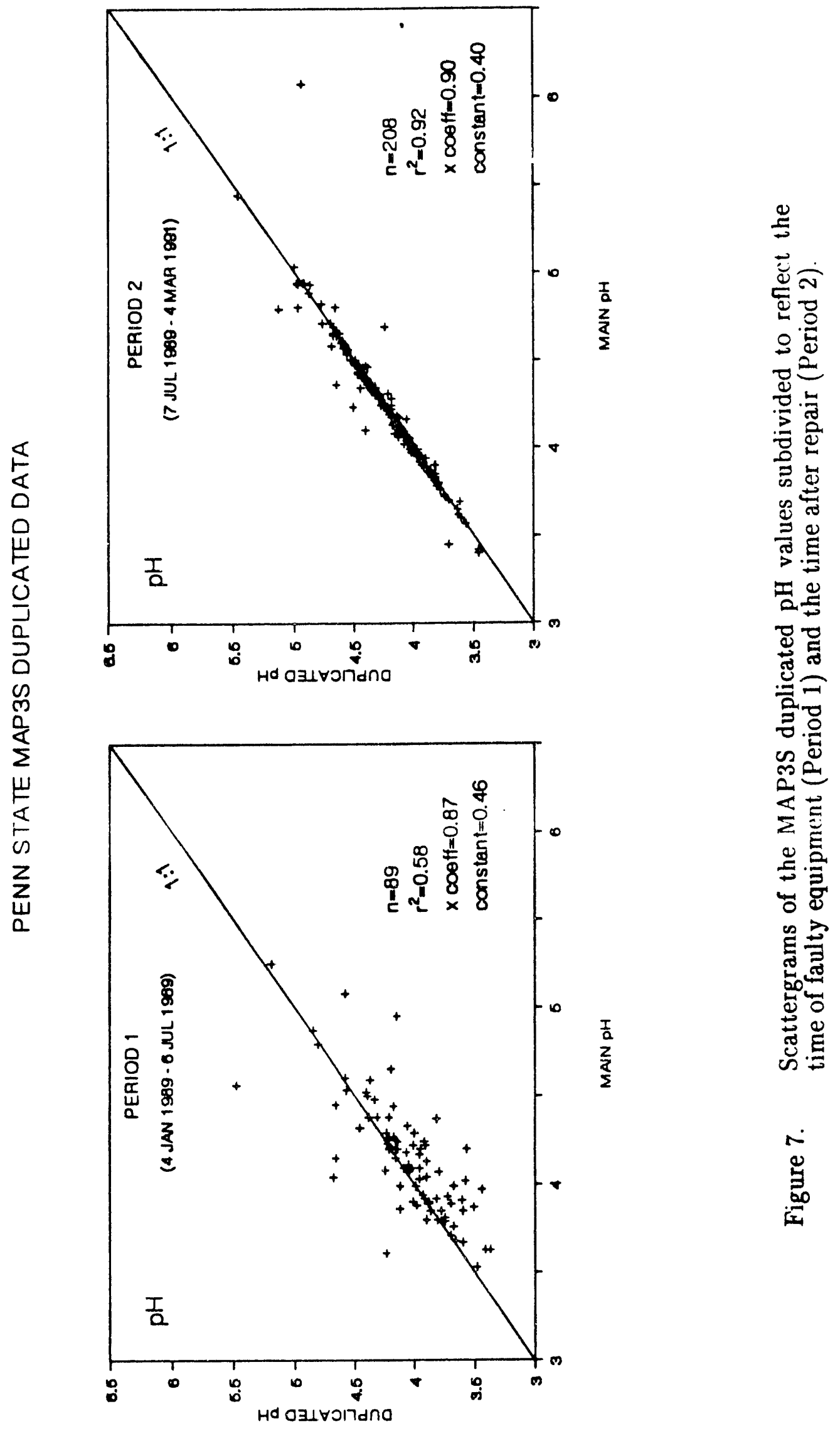


6 July 1989) and for the second period (7 July 1989 to 4 March 1991). The bias toward lower $\mathrm{pH}$ values in the duplicated samples is clearly evident in the first period. The large improvement in data quality is readily apparent in the second period after the repair of the equipmeni.

Both parametric and nonparametric statistical analyses of the difference data sets derived from the two sampling periods were used to determine the magnitudes of the biases and precisions of these measurements. As shown by the results in Table 2, the volume and depth data are consistently good, exhibiting coefficients of variation (standard deviation/mean) of about $4 \%$. On the other hand, a significant bias in the $\mathrm{pH}$ data occurred during the first period before the lid gasket was replaced, and the standard deviation was about a quarter of a $\mathrm{pH}$ unit. As shown by the second-period results, when equipment are working properly and all protocols adhered to, any important bias disappears and the standard deviation in $\mathrm{pH}$ is close to 0.1 unit.

MAPSS - NADP/NTN Intercomparison. Similar statistical analyses have been applied to comparisons of data derived from other networks and different sampling protocols. In a study of CAPMoN and NADP/NTN data that was completed recently (Vet et al., 1989), statistically significant biases were found to exist in some of the measurement variables (precipitation depth, $\mathrm{H}_{3} \mathrm{O}^{+}, \mathrm{pH}, \mathrm{NO}_{3}^{-}$, and $\mathrm{NH}_{4}^{+}$). Some notable differences from these results exist when the MAP3S data are compared with the NADP/NTN data over a longer sampling history. By way of example, a scatter plot (Fig. 8) of the weekly NADP/NTN $\mathrm{H}_{3} \mathrm{O}^{+}$concentrations against weekly composites of the MAP3S data shows some scatter but no bias. By contrast, a similar presentation of sulfate concentrations (Fig. 9) reveals a minor, but statistically significant bias. A summary of the statistical findings for these and other pertinent variables is presented in Table 3. Additional details are provided in Appendix I. Despite the differences between these findings and those of the CAPMON-NADP/NTN intercomparison, it is safe to conclude 
Table 2. Bias, precision (PREC) and coefficient of variation (CV) estimates between MAP3S ma:n and duplicated data (duplicated-main)

\begin{tabular}{|c|c|c|c|c|c|c|c|}
\hline & \multirow[b]{2}{*}{$N$} & \multicolumn{3}{|c|}{ PARAMETRIC } & \multicolumn{3}{|c|}{ NON-PARAMETRIC } \\
\hline & & $\begin{array}{l}\text { BIAS } \\
\text { (mean) }\end{array}$ & $\begin{array}{l}\text { PREC } \\
\text { (std.dev.) }\end{array}$ & $\mathrm{CV} \%$ & $\begin{array}{l}\text { BIAS } \\
\text { (median) }\end{array}$ & $\begin{array}{l}\text { PREC } \\
\text { (M.MAD) }\end{array}$ & CV \% \\
\hline & \multicolumn{7}{|c|}{ Period 1 (4 Jan 1989 - 6 Jul 1989) } \\
\hline Depth (mm) & 89 & -0.04 & 0.27 & 4 & -0.00 & 0.15 & 4 \\
\hline $\mathrm{pH}$ & 89 & $-0.08^{\mathrm{a}}$ & 0.25 & -.- & $-0.06^{b}$ & 0.12 & -.- \\
\hline $\mathrm{H}_{3} \mathrm{O}^{+}$Conc (uM) & 89 & $25.63^{\mathrm{a}}$ & 60.62 & 59 & $9.85^{\mathrm{b}}$ & 19.95 & 24 \\
\hline \multicolumn{2}{|c|}{$\mathrm{H}_{3} \mathrm{O}^{+}$Dep(umol.m $\left.{ }^{-2}\right) 87$} & $58.08^{\mathrm{a}}$ & 131.04 & 26 & $16.10^{\mathrm{b}}$ & 50.88 & 21 \\
\hline
\end{tabular}

Period 2 (7 Jul 1989 - 4 Mar 1991)

\begin{tabular}{lrllllll} 
Depth (mm) & 208 & $0.04^{\mathrm{a}}$ & 0.26 & 3 & 0.02 & 0.12 & 3 \\
$\mathrm{pH}$ & 208 & -0.04 & 0.10 & $\ldots$ & 0.00 & 0.02 & $\ldots$ \\
$\mathrm{H}_{3} \mathrm{O}^{+}$Conc (uM) & 208 & -0.54 & 13.47 & 17 & 0.00 & 2.71 & 4 \\
$\mathrm{H}_{3} \mathrm{O}^{+}$Dep(umol.m & -2 \\
\hline
\end{tabular}

a indicates significance at the $95 \%$ confidence level using the Student's $t$ test

b indicates significance at the $95 \%$ confidence level using the sign test

${ }^{*}$ M.MAD $=\frac{1}{0.6745}$ median $\left|\Delta \mathrm{X}_{\mathrm{k}}-\Delta \mathrm{X}_{\text {median }}\right|$ 


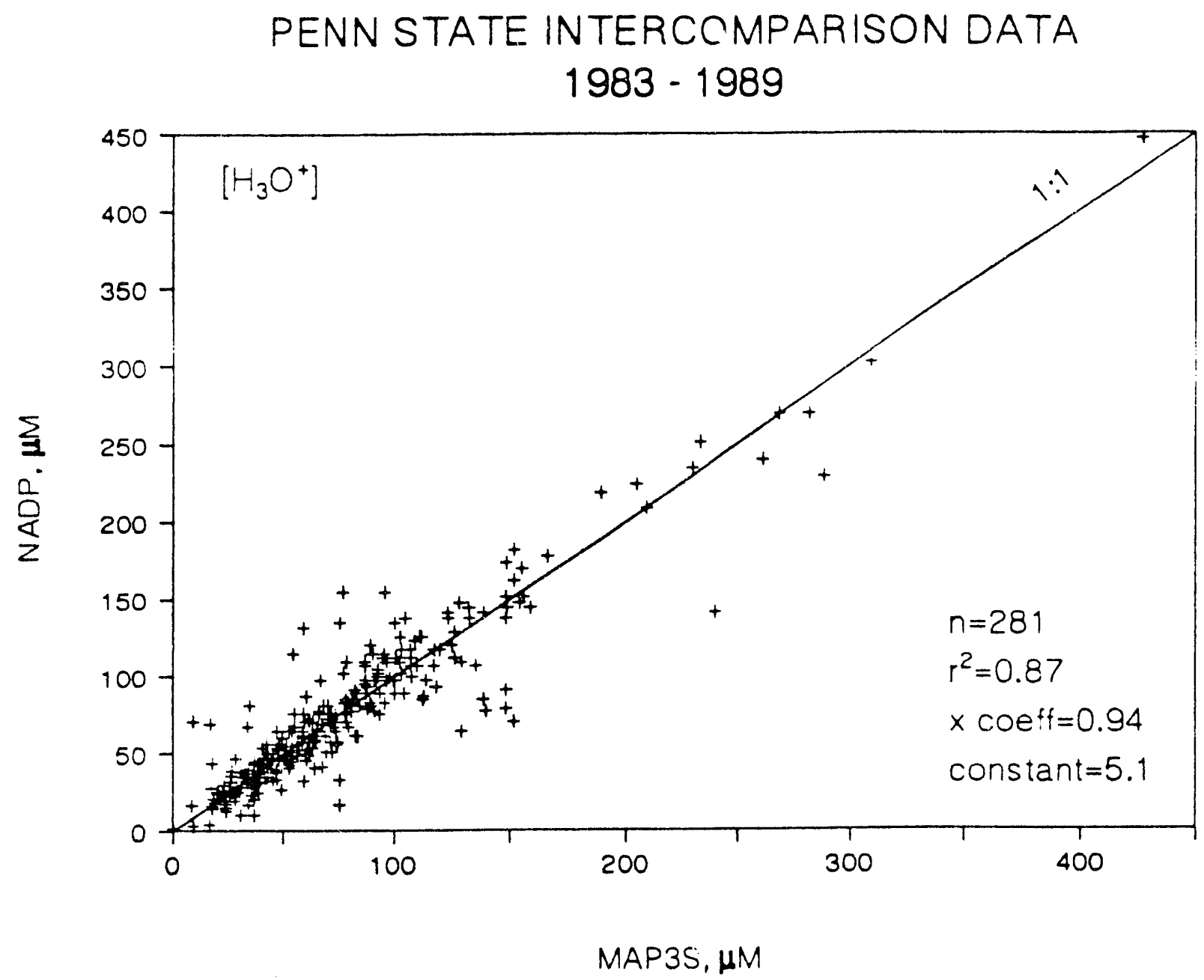

Figure 8. Scattergram of hydronium concentration. 


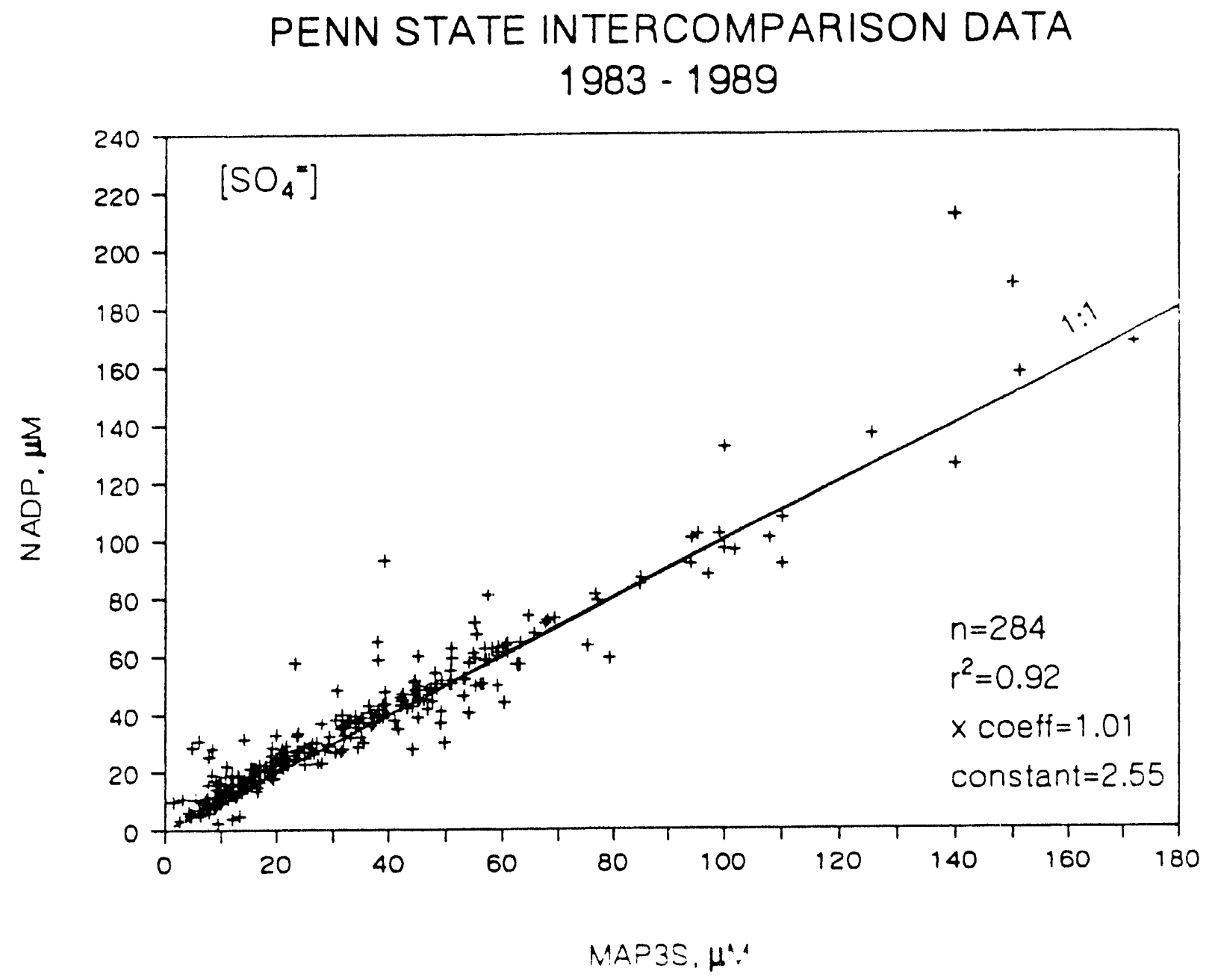

Figure 9. Scattergram of sulfate concentration. 
Table 3. Bias, precision (PREC) and coefficient of variation (CV) estimates of concentration and deposition differences (MAP3S-IADP)

\begin{tabular}{|c|c|c|c|c|c|c|c|}
\hline & \multirow[b]{2}{*}{$\mathrm{N}$} & \multicolumn{3}{|c|}{ PARAMETRIC } & \multicolumn{3}{|c|}{ NON-PARAMETRIC } \\
\hline & & $\begin{array}{l}\text { BIAS } \\
\text { (mean) }\end{array}$ & $\begin{array}{l}\text { PREC } \\
\text { (std.dev.) }\end{array}$ & $\mathrm{CV} \%$ & $\begin{array}{l}\text { BIAS } \\
\text { (median) }\end{array}$ & $\begin{array}{l}\text { PREC } \\
\text { (M.MAD }\end{array}$ & $\begin{array}{l}\text { CV \% } \\
*\end{array}$ \\
\hline & & \multicolumn{6}{|c|}{ Concentration } \\
\hline $\mathrm{H}_{3} \mathrm{O}^{+}(\mathrm{uM})$ & 266 & 0.37 & 19.35 & 25.0 & -0.00 & 11.74 & 18.1 \\
\hline $\mathrm{SO}_{4}=(\mathrm{uM})$ & 281 & $-2.69^{a}$ & 8.69 & 23.7 & $-2.13^{b}$ & 3.31 & 11.6 \\
\hline $\mathrm{NO}_{3}{ }^{-}(\mathrm{uM})$ & 280 & -0.73 & 12.86 & 30.7 & $-1.26^{b}$ & 4.36 & 12.0 \\
\hline $\mathrm{NH}_{4}{ }^{+}(\mathrm{uM})$ & 267 & $2.79^{a}$ & 9.26 & 49.3 & $1.42^{b}$ & 4.00 & 26.2 \\
\hline \multirow[t]{2}{*}{ P.DPT (mm) } & 321 & 0.19 & 4.28 & 21.1 & 0.03 & 0.64 & 4.3 \\
\hline & \multicolumn{7}{|c|}{ Deposition } \\
\hline $\mathrm{H}_{3} \mathrm{O}^{+}(\mathrm{uM})$ & 263 & -24.43 & 533.58 & 34.2 & -0.49 & 212.50 & 19.8 \\
\hline $\mathrm{SO}_{4}=(\mathrm{uM})$ & 277 & $-36.49^{a}$ & 211.83 & 30.1 & $-22.54^{b}$ & 61.60 & 14.1 \\
\hline $\mathrm{NO}_{3}^{-}(\mathrm{uM})$ & 277 & -5.51 & 234.44 & 34.1 & $-16.65^{b}$ & 66.55 & 13.0 \\
\hline $\mathrm{NH}_{4}{ }^{+}(\mathrm{uM})$ & 264 & $57.52^{\mathrm{a}}$ & 223.63 & 60.5 & $14.81^{b}$ & 73.14 & 37.6 \\
\hline
\end{tabular}

a indicates significance at the $95 \%$ confidence level using the Student's $t$ test

$b$ indicates significance at the $95 \%$ confidence level using the sign test

${ }^{*}$ M.MAD $=\frac{1}{0.6745}$ median $\left|\Delta \mathrm{X}_{\mathrm{k}}-\Delta \mathrm{X}_{\text {median }}\right|$ 
that the data from each of these three networks are of reasonably high quality and reflect the natural variability of the atmosphere.

\section{The Data Record}

The MAP3S data represent a relatively long, continuous record of the climatology of various trace chemicals in precipitation. Figure 10 presents the annual wet-deposition flux of the four most important ions measured in precipitation collected at the Penn State MAP3S site. The bold line shows the trend and year-to-year variability to the deposition of free acidity. In a general sense, it is apparent that the interannual variability in acidity reflects that of the deposition of sulfate and water (precipitation). Given the recent determinations of MAP3S measurement precision (for deposition of acidity, at least), the indicated trends must be considered to be "real" to within better than $10 \%$ and due to variations in sulfur emissions, $\mathrm{SO}_{2}$-oxidation efficiencies, precipitation scavenging efficiencies, meteorological flow patterns, or, most likely, some combination of all of these factors.

Investigations into the sources of the acidity found in the precipitation in this region have also constituted an active research area. Statistical correlations between the concentration of the hydronium ion and the concentrations of various inorganic ions have traditionally shown the $\mathrm{SO}_{4}{ }^{2-}$ ion to be primarily responsible for the acidity in rain, while the $\mathrm{NO}_{3}{ }^{-}$ions seems to be the controlling factor in snow (Bowersox and de Pena, 1980). A subset of the MAP3S data that was recently acquired for comparison with aerosol and trace gas measurements confirms this conclusion, at least for rain (Fig. 11). The relative proportion of the various inorganic ions found in the same precipitation samples is shown on a molar basis in Fig. 12.

The sulfate that gives rise to the pronounced acidity in the precipitation could conceivably enter the precipitation directly from the ambient aerosol, either in cloud or below cloud. As shown in Fig. 13, a fairly large mole fraction of the atmospheric aerosol is 


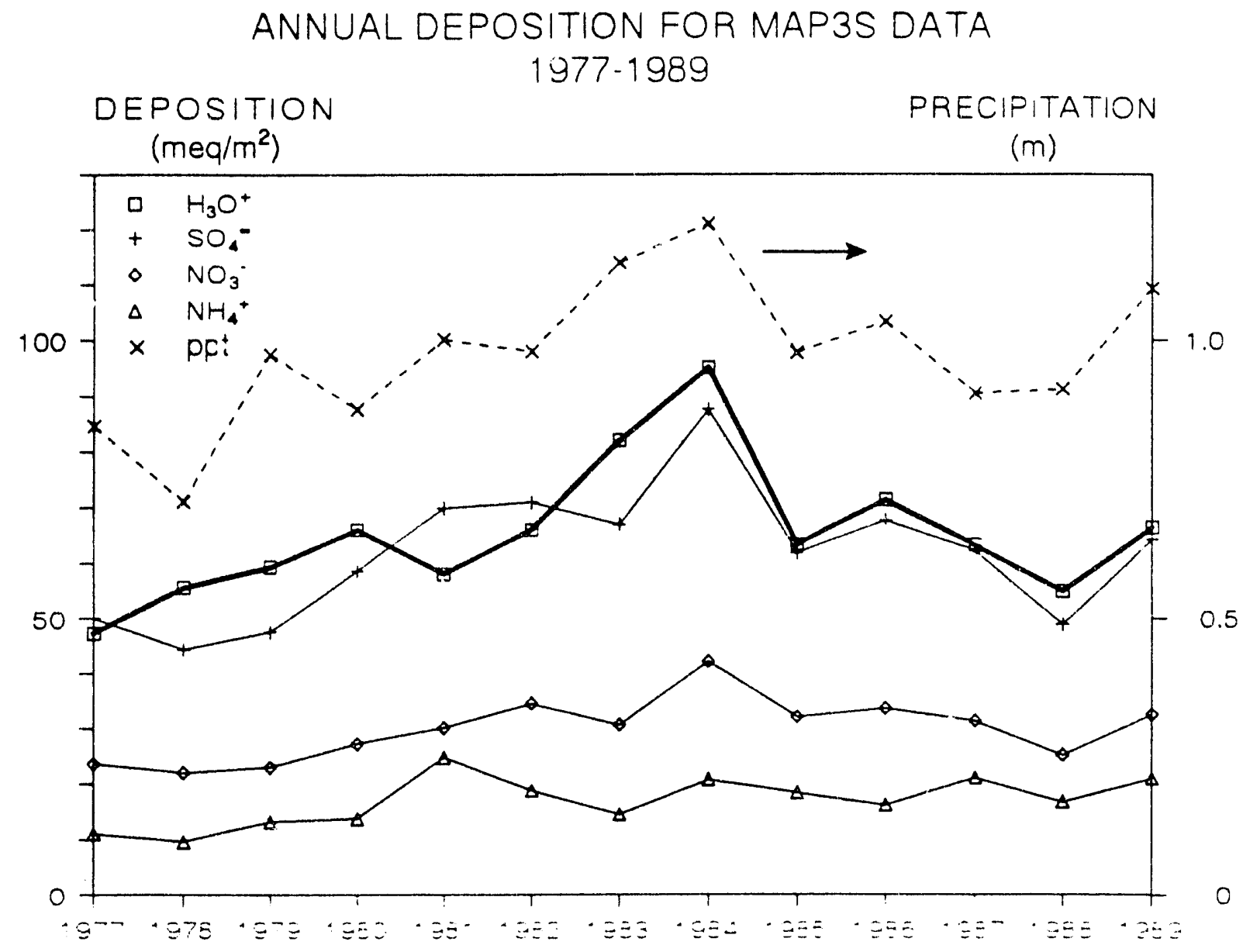

Figure 10. Annual deposition of major ions and precipitation during MAP3S. 


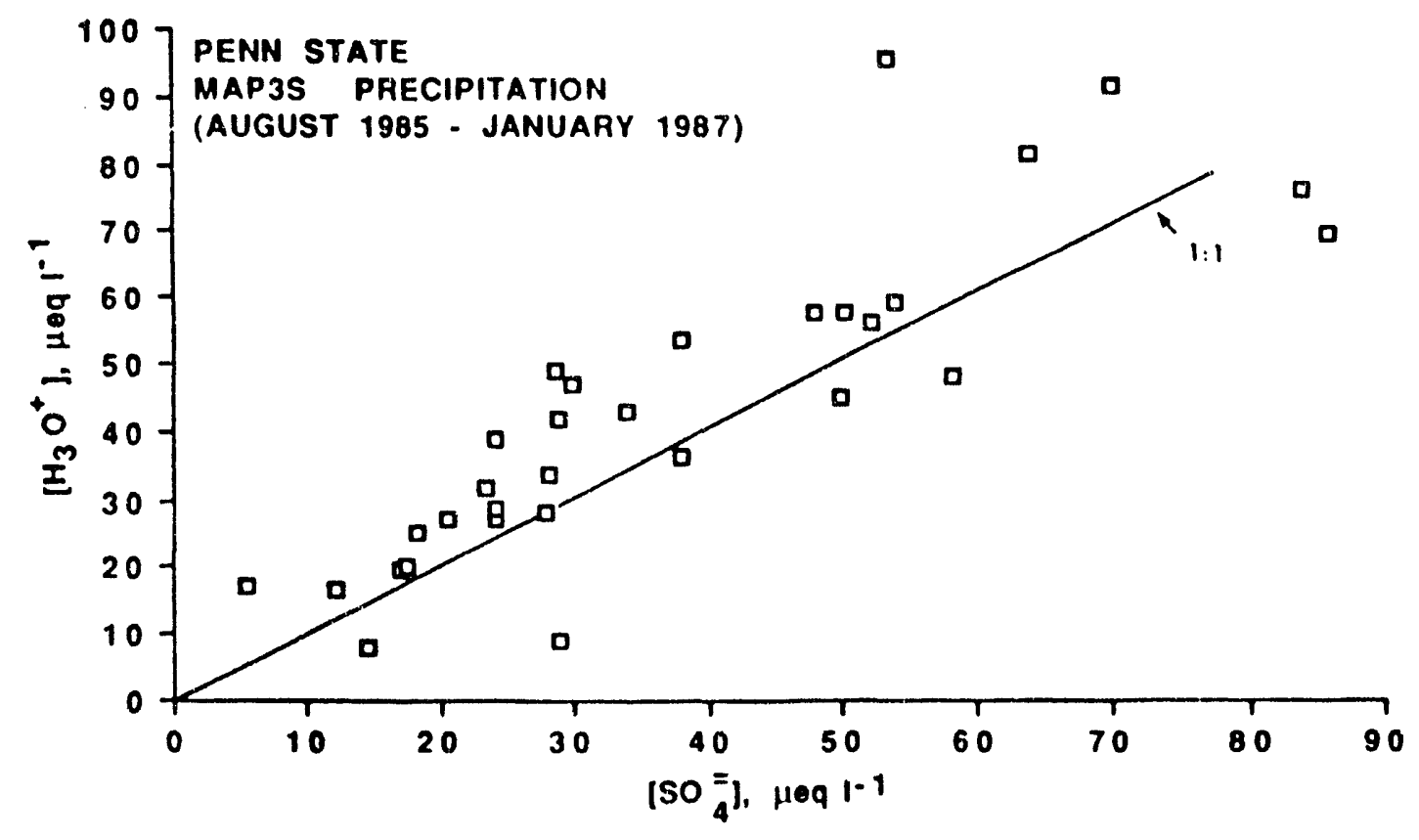

Figure 11. The relationship between the concentrations of the hydronium and sulfate ions during selected events between August 1985 and January 1987. 


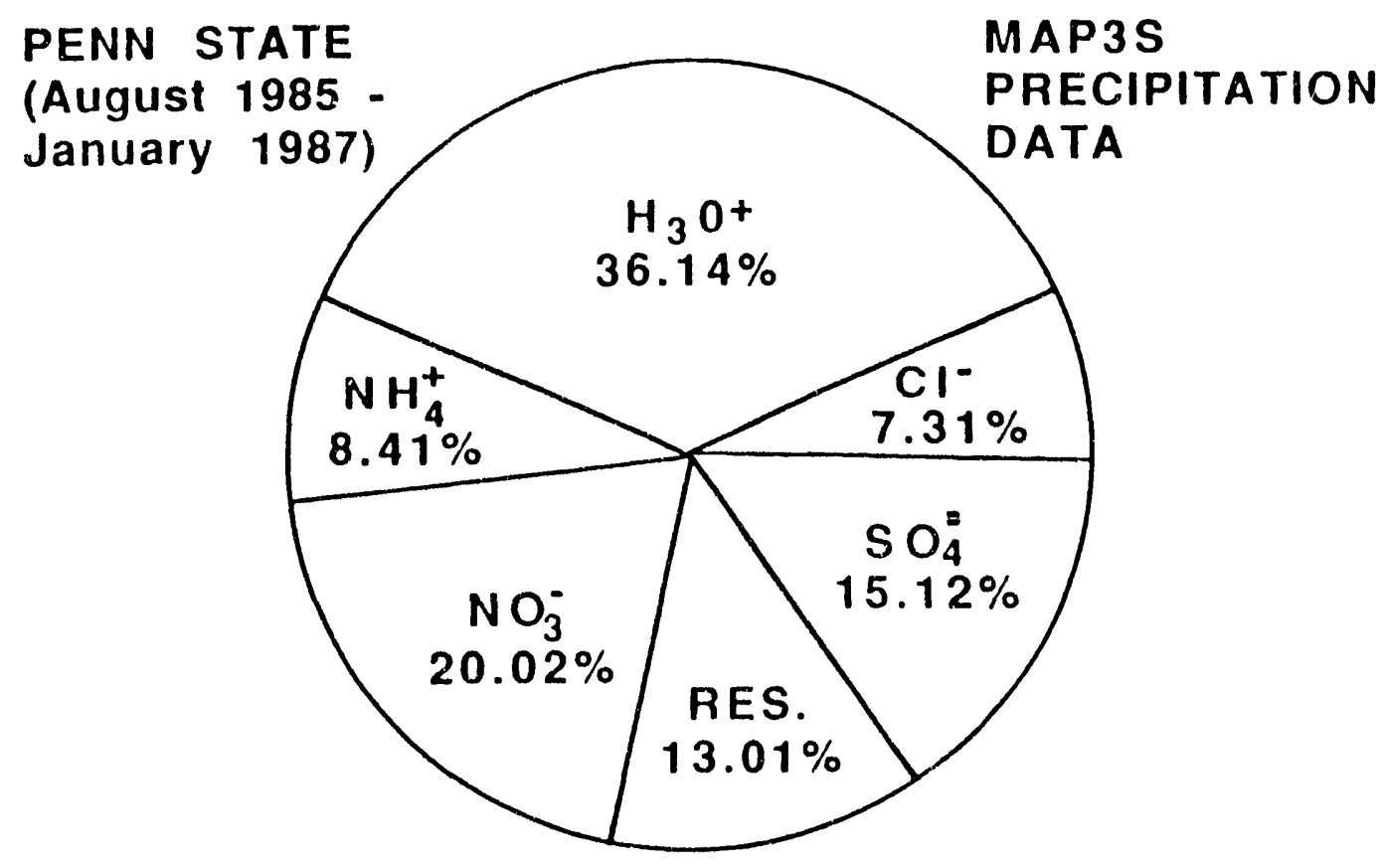

Figure 12. The relative composition of inorganic ions in MAP3S precipitation expressed as mole percentages. RES refers to the residual components needed to balance the ionic charges. 


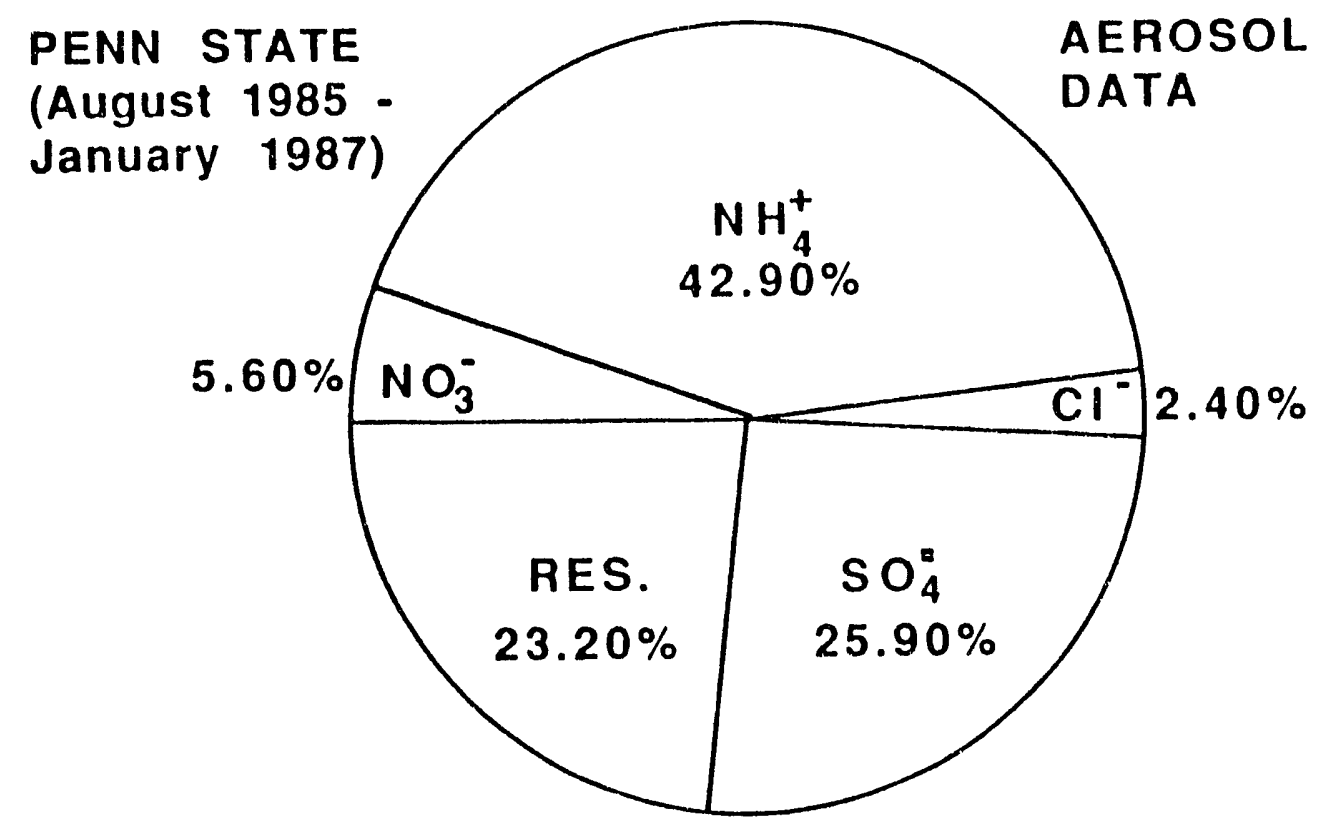

Figure 13. The relative composition of ions in aerosol samples expressed as mole percentages. RES refers to the residual components needed to balance the ionic charges. 
composed of sulfate, even in this data set which emphasized winter storm systems. However, due largely to the neutralizing effects of $\mathrm{NH}_{4}{ }^{+}$, there is insufficient free acidity available in the aerosol to account for that actually found in the precipitation. The in-cloud oxidation of $\mathrm{SO}_{2}$ is therefore thought to be an important contributing factor and will be discussed later.

If we can argue that the measured deposition data reflect natural events in the atmosphere, we should be able, because the MAP3S data are taken at the level of individual meteorological events, to identify at least part of the reasons for the observed variability. By way of example, we may consider the particularly large deposition of sulfate (and therefore of $\mathrm{H}_{3} \mathrm{O}^{+}$) that occurred during the 1984 calendar year (refer to Fig. 10). Breaking the same data set apart by season, as shown in Figs. 14 and 15, we see that 1984 at the Penn State site was characterized by a summer of unusually large depositions of $\mathrm{H}_{3} \mathrm{O}^{+}$and sulfate. As seen in the mol.thly averages of Fig. 16, the summer months of June, July and August commonly yield large deposition of sulfate, probably because of the greater availability on average of photochemical oxidants (particularly $\mathrm{H}_{2} \mathrm{O}_{2}$ ) during the warm season. When the actual monthly deposition of sulfate is plotted for each month of each year, as in Fig. 17, we see that August 1984 experienced a large deviation (by nearly a factor of three) from the monthly average.

\section{Trajectory Analyses}

Throughout the course of the MAP3S program at Penn State there has been a deep awareness of the important role played by the meteorology in transporting the trace constituents from their source regions to the vicinity of the precipitation deposition site. Detailed comparisons of the composition of precipitation collected on a sub-event basis with the integrated source strengths of acid precursors along given air trajectories have indicated that a substantial portion of the pollutants enters the atmosphere hundreds of kilometers "upwind" (de Pena et al., 1984). Such studies have pointed to the need to find 


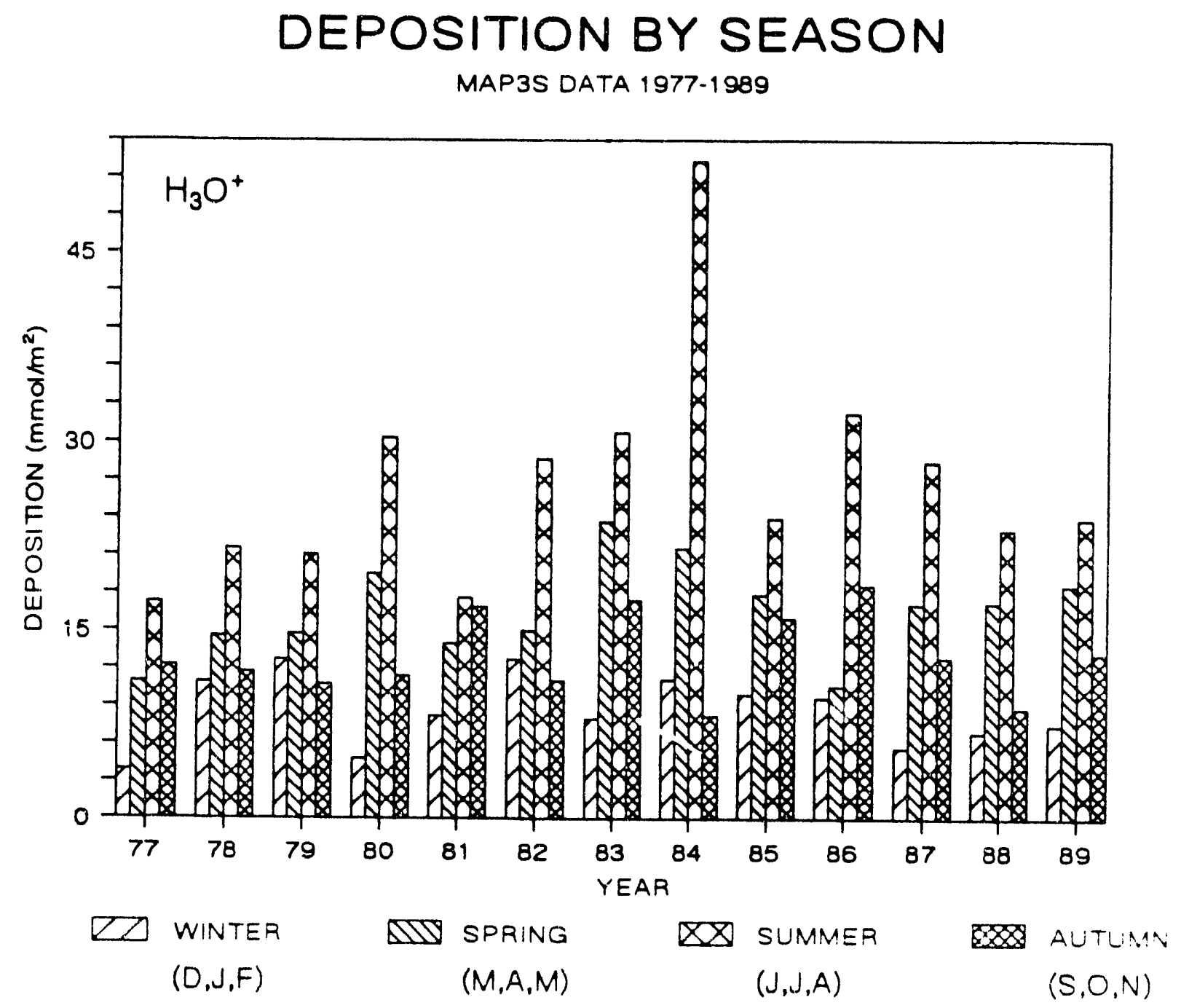

Figure 14. Annual deposition of hydronium subdivided into seasons. 


\section{DEPOSITION BY SEASON \\ MAP3S DATA 1977-1989}

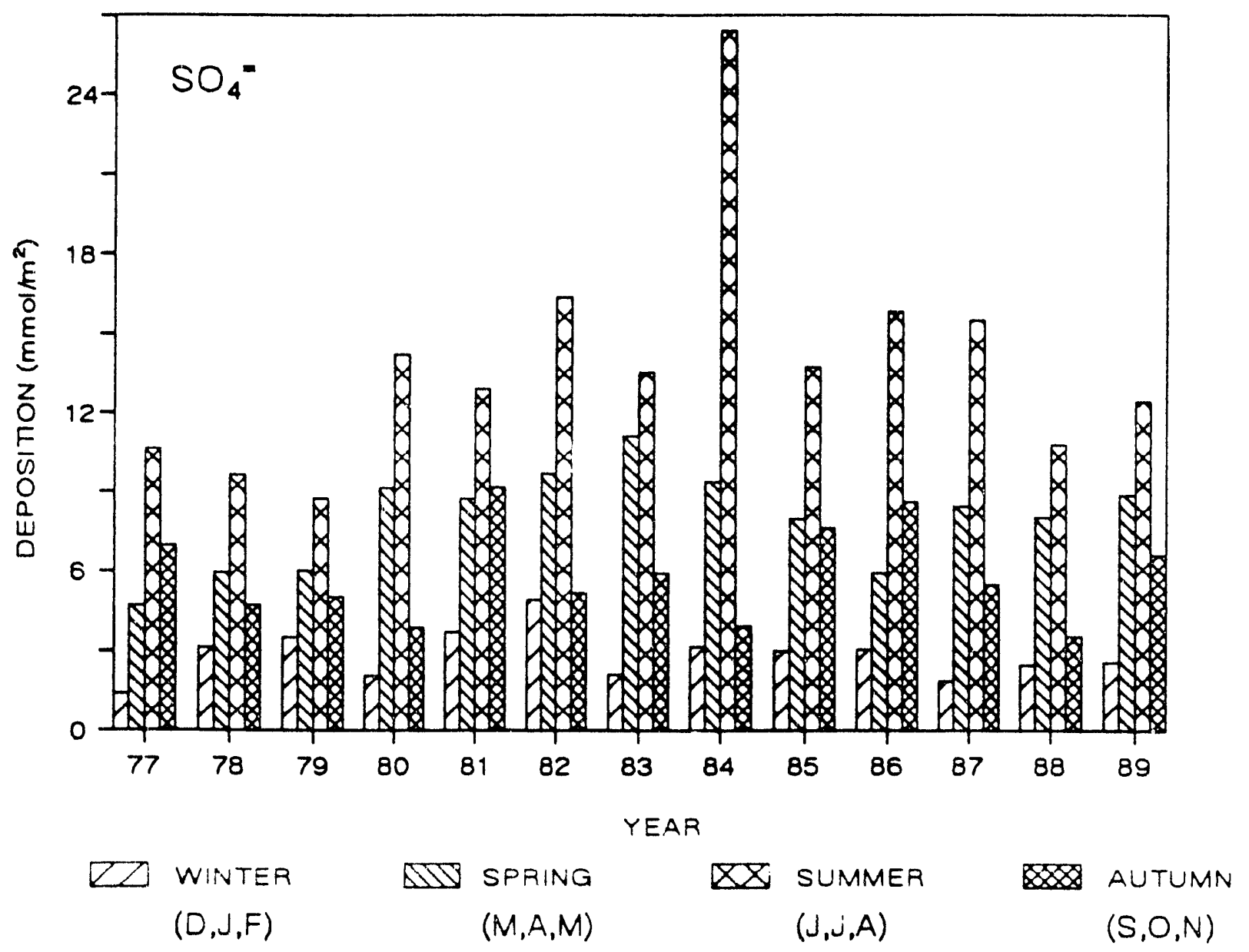

Figure 15. Annual deposition of sulfate subdivided into seasons. 


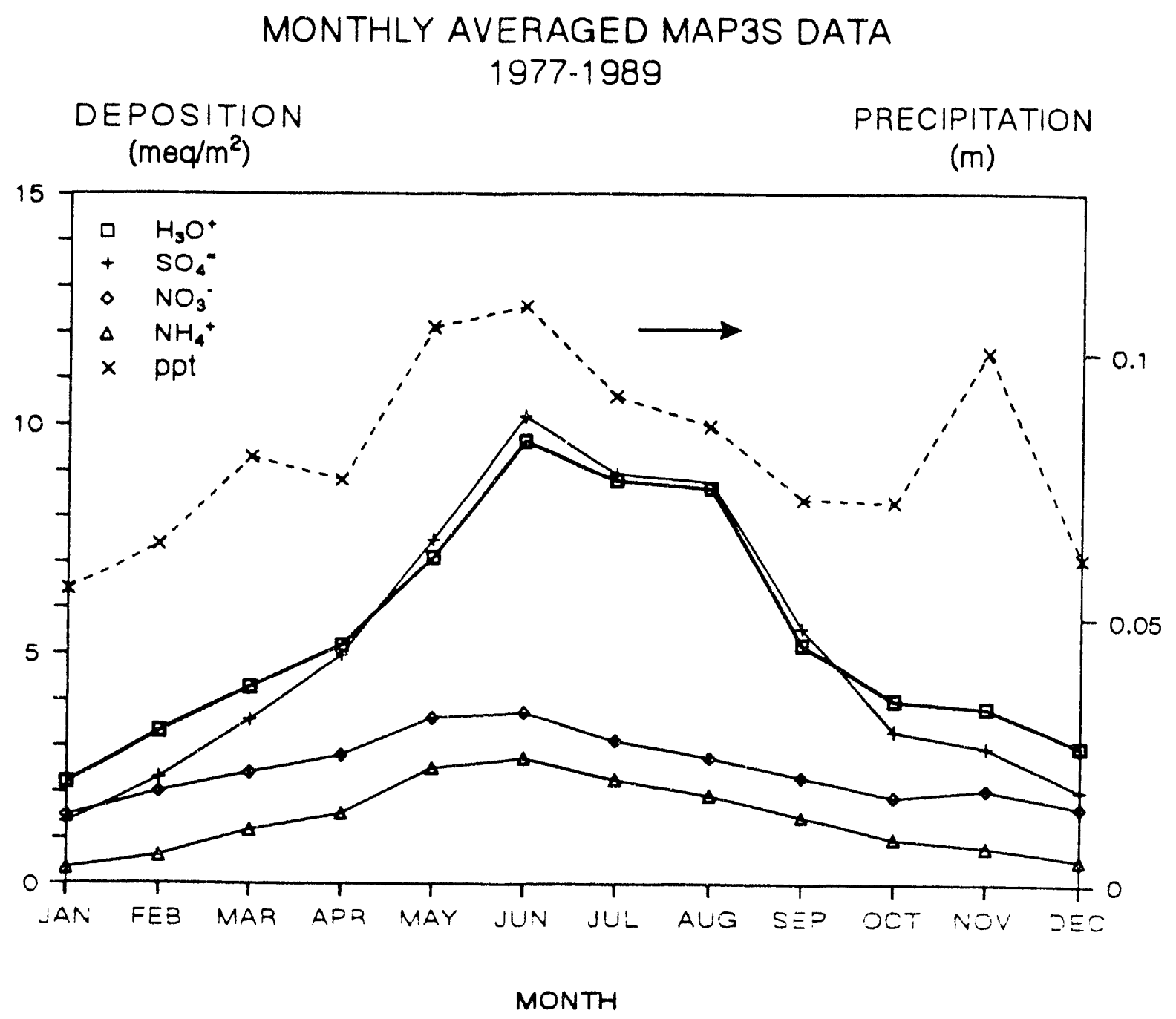

Figure 16. Monthly averaged deposition and precipitation data. 


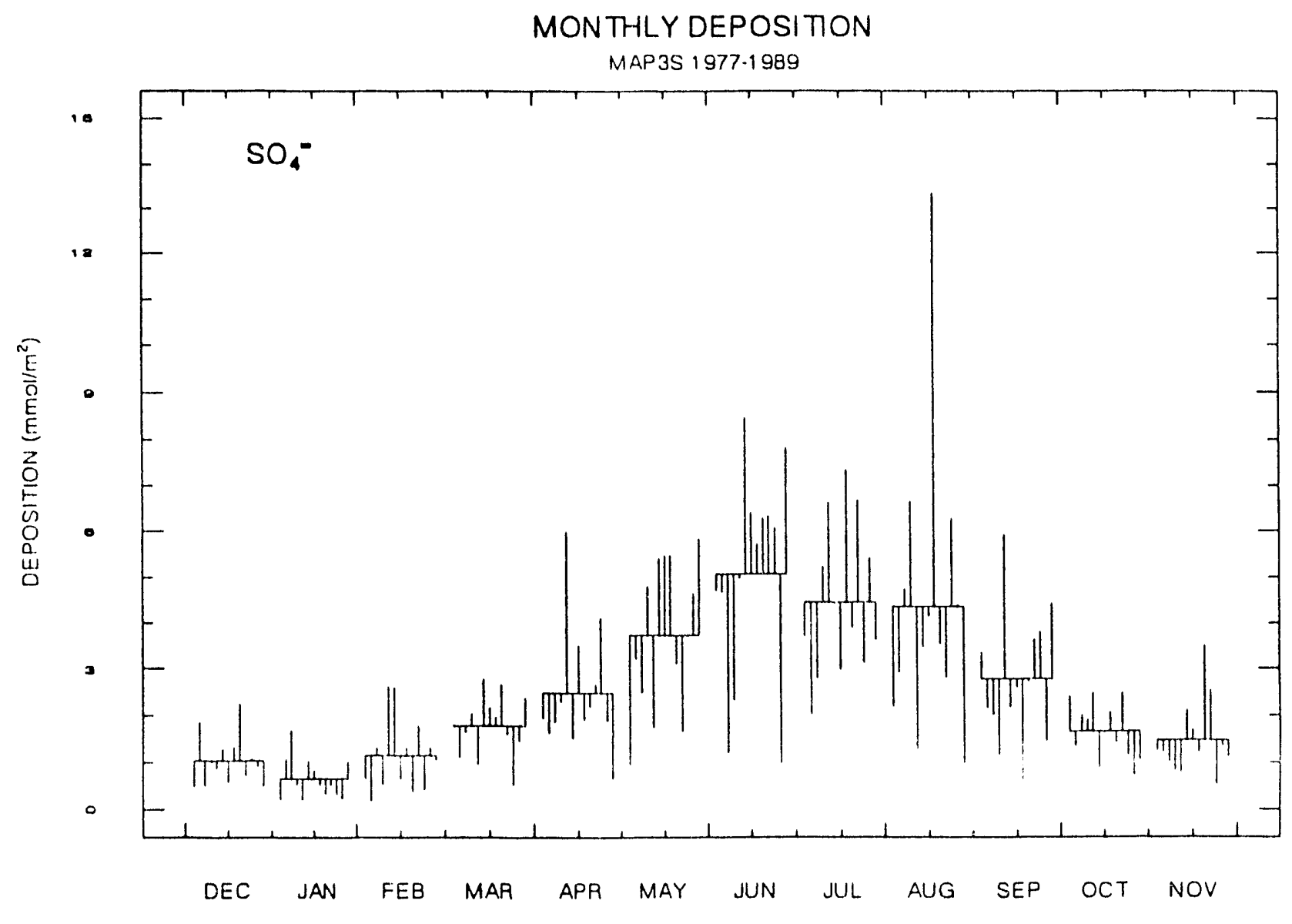

Figure 17. Deviations of monthly sulfate deposition from the monthly means. 
new ways to improve our techniques for calculating back trajectories from meteorological data (de Pena et al., 1986).

Part of the reason for the large deposition anomaly in August 1984, for instance, lies in the meteorological flow patterns that prevailed at the time. Detailed analysis of the MAP3S data for that month revealed a number of unusually high-deposition events, combinations of large storm precipitation amounts and high sulfate concentrations (despite the tendency for dilution by large quantities of water). Figure 18 shows the air trajectory calculated just prior to one of the high-deposition events from standard meteorological winds with a single-layer version of the NOAA-ARL Branching Atmospheric Trajectory (BAT) model (Heffter, 1983). The warm, moist air that spawned the storm in question passed along the emissions-rich Ohio Valley during the two days prior to the rain event at State College, PA (square symbol). Apparently, the fresh $\mathrm{SO}_{2}$ released into the air during its passage over the various sources was effectively oxidized to sulfate and scavenged by the copious precipitation that fell in this region. By contrast, the air that brought significant rain during one of the relatively low-deposition events (trajectory shown in Fig. 19) came in from the Atlantic Ocean and across the east coast of the United States, where either emissions of $\mathrm{SO}_{2}$ or oxidation potential are less. Through such analysis of the MAP3S data, in conjunction with standard meteorological data, it is possible to understand, to some extent at least, the physical causes of the long-term climatology of precipitation chemistry. It must be appreciated that such a resolution of climatological data is possible only with data that are taken on an event or subevent basis. Herein lies one of the major strengths of the MAP3S protocol. Note, for instance, that the high-and low-deposition events discussed here occurred only five days apart and would not normally be resolvable from samples gathered on a weekly basis. 


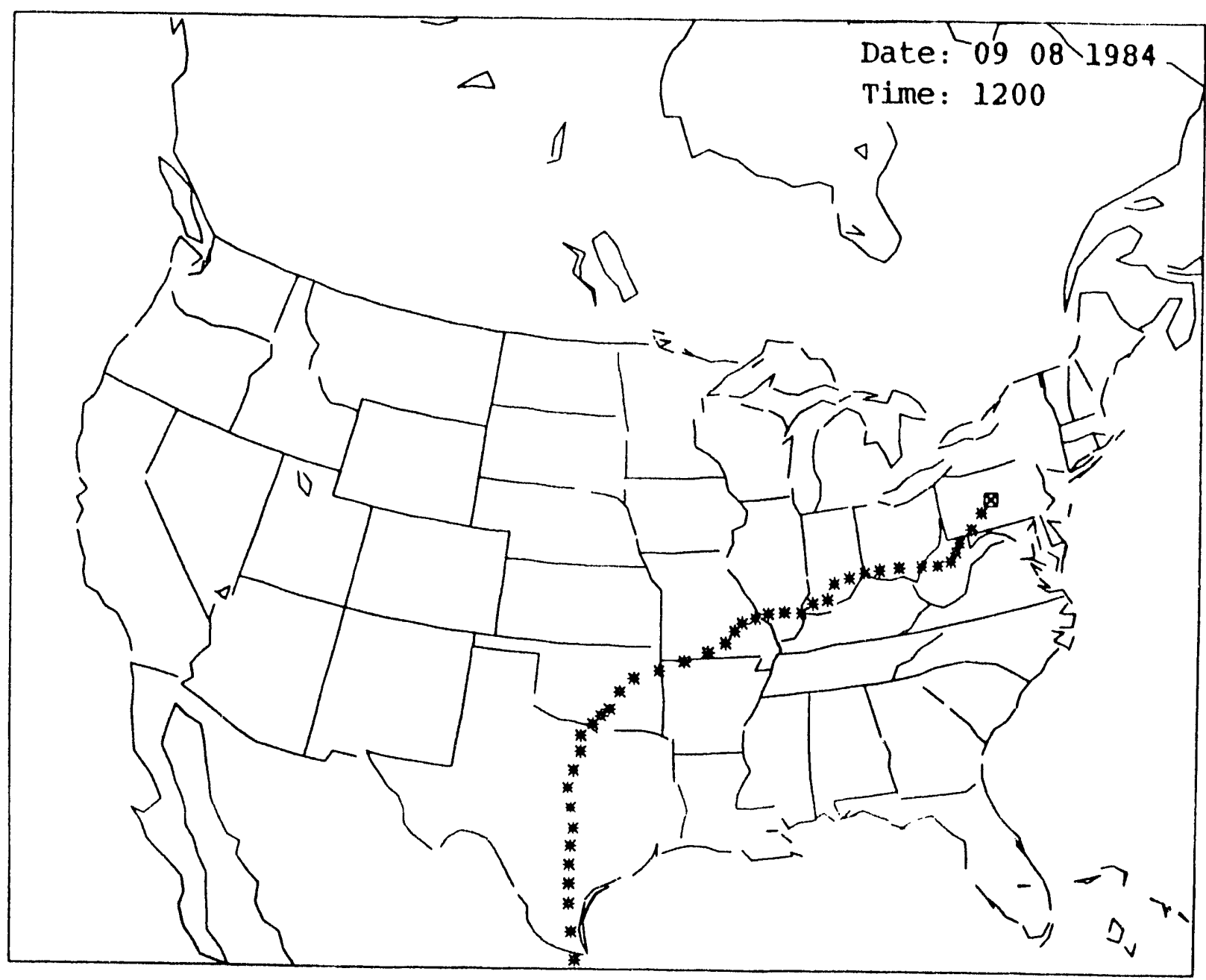

Figure 18. Back trajectory of air arriving at the Penn State site preceding a high-deposition event. 


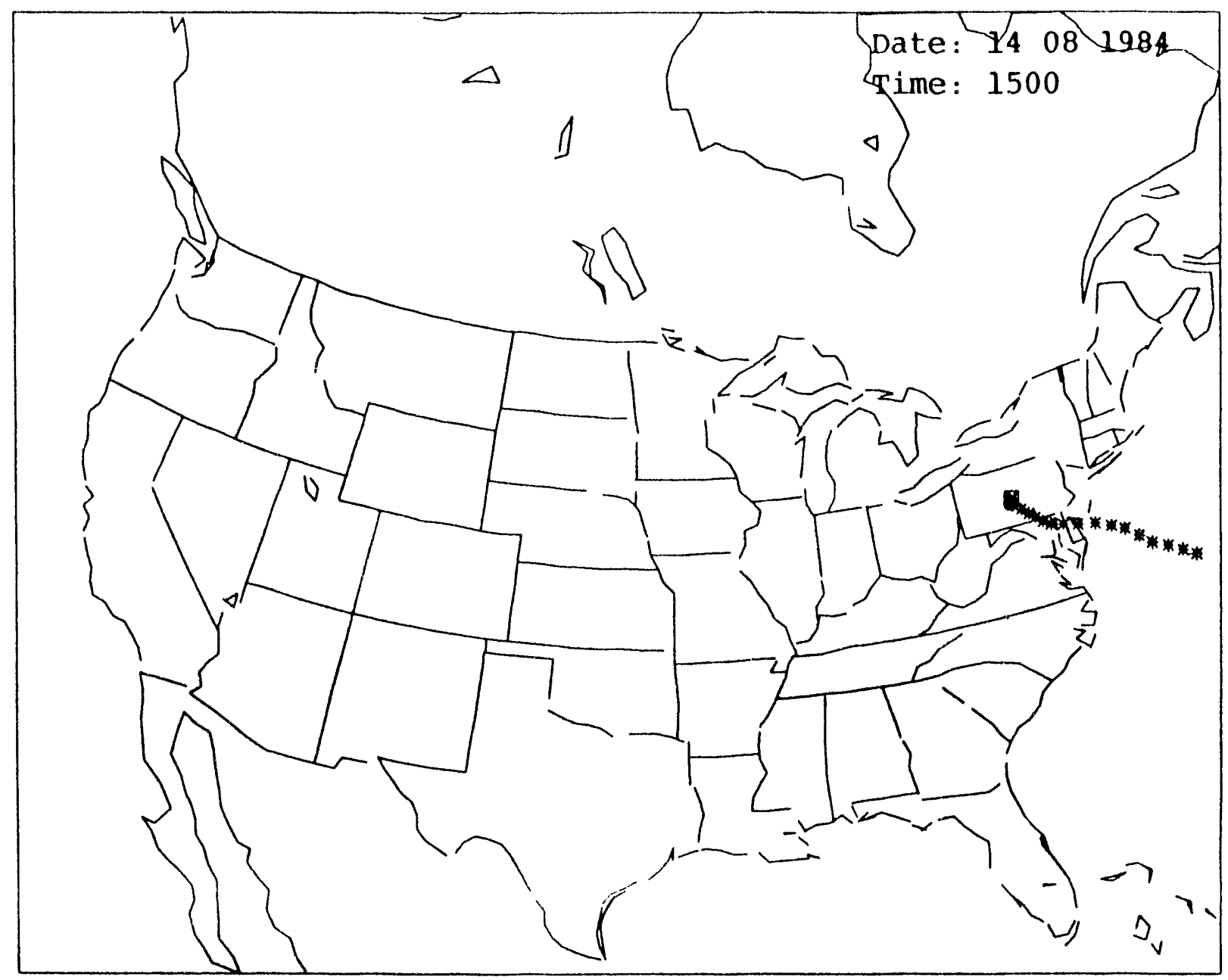

Figure 19. Back trajectory of air arriving at the Penn State site preceding a low-deposition event. 


\section{4. $\quad$ Sulfate Scavenging}

Sulfate appears in precipitation in this region of the continent largely through the oxidation of $\mathrm{SO}_{2}$ and the incorporation of the resulting sulfate into precipitation. Some of the chemical conversion of $\mathrm{SO}_{2}$ to sulfate occurs in clear air via gas-phase reactions, but the large aqueous-phase concentrations afforded by clouds allows for heterogeneous transformations to take place concurrently with the precipitation-scavenging process (Lamb et al., 1987). Thus, under favorable circumstances, as when cloud forms in humid air rich in photochemical oxidants, recently released $\mathrm{SO}_{2}$ may be oxidized rapidly within cloud, a process that serves to enrich the precipitation in sulfate relative to the amount contributed by the precloud aerosol sulfate alone.

In order to address the issues of $\mathrm{SO}_{2}$ oxidation and removal by precipitating clouds, special measurements were taken in conjunction with specific meteorological events. Details are presented by Brooks and Lamb (1990). In essence, the aerosol at the site was sampled and analyzed for sulin's and lead, while the concentrations of gaseous $\mathrm{SO}_{2}$ and water vapor were also measured in the air thought to best represent that entering the storm system from which rain was to be collected. The precipitation samples were separately collected and analyzed for sulfate and lead in specially prepared buckets. Enrichment factors were calculated from comparison of the air and precipitation concentrations. With the essential assumption that lead resides in submicron particles and is scavenged by cloud and precipitation with the same efficiency that aerosol sulfate is, these measurements allow the sulfate appearing in the precipitation sample to be resolved into contributions from precloud aerosol sulfate and from in-cloud $\mathrm{SO}_{2}$ oxidation. The method follows that of Meszaros and Szentimrei (1985) except that individual events were sampled with particular attention paid to the meteorology prevailing at the time.

The results of this research confirm the important role played by in-cloud oxidation. Within the constraints imposed by the various assumptions of the method, it is found that a very high percentage $(>90 \%)$ of the sulfate in precipitation may be derived from 
in-cloud transformations of $\mathrm{SO}_{2}$. Moreover, the relative removal efficiency of $\mathrm{SO}_{2}$ from the atmosphere by warm-frontal systems seems to be particularly high. This may be explained perhaps by the longer time air spends in cloud in that part of a typical cyclonic storm (Fig. 20). Also, with a favorable juxtaposition of air trajectories over $\mathrm{SO}_{2}$ sources and sampling location in relationship to the overall storm structure, one should expect high sulfate and acid deposition events to occur in this region (Lamb and Comrie, 1991; Appendix II). Excess $\mathrm{SO}_{2}$ not deposited is likely to exit the storm at high levels in the troposphere and be exported from the continent of origin.

\section{v. CONCLUSIONS}

The MAP3S protocol has proven to be extremely valuable for defining the chemical climatology of precipitation in the eastern region of the United States. The long record now available allows us to recognize that acidic precipitation is an ongoing phenomenon linked to anthropogenic emissions of $\mathrm{SO}_{2}$ in the region. Unfortunately, the MAP3S program is in danger of dying just at a time when emissions are scheduled to fall significantly. It may be difficult to demonstrate changes in deposition trends from data collected with different protocols.

The MAP3S data have also proven to be invaluable for investigating the atmospheric processes responsible for wet deposition. The strength of the MAP3S protocol has been in its ability to resolve individual meteorological events, although a decided weakness has been the lack of a simultaneous record of pollutant concentrations in the air. 
Page 35 intentionally left blank 
The MAP3S data clearly demonstrate that the acidity in precipitation in the eastern United States is derived from unneutralized sulfate in the precipitation. Since there are no significant direct sources of sulfate in the region, it is generally thought that the sulfate arises from the oxidation of $\mathrm{S}(\mathrm{IV})$ compounds, mostly $\mathrm{SO}_{2}$, in the clear or cloudy air. The enrichment studies conducted at t:e Penn State MAP3S site indeed give strong evidence that the precipitation sulfate is due to the in-cloud oxidation of $\mathrm{SO}_{2}$. Given the great body of research that points to the important roles played by the strong oxidants, $\mathrm{H}_{2} \mathrm{O}_{2}$ and $\mathrm{O}_{3}$, and the limited availability or reactivity of these oxidants, we conclude that the deposition of sulfate and free acidity at acidic sites is modulated primarily by the variability in the strong oxidant abundances. Therefore, the scheduled reductions in $\mathrm{SO}_{2}$ emissions will not be reflected in the deposition of acidity unless oxidant levels are also reduced. The changes in the emissions patterns are most likely to impact the flux of unoxidized S(IV) that exits synoptic-scale storm systems passing through source-rich regions such as the eastern United States. 


\section{REFERENCES}

Bowersox, V.C., and R.G. de Pena, 1980: Analysis of precipitation chemistry at a central Pennsylvania site. J. Geophys. Res., 85, 5614-5620.

Brooks, L., and D. Lamb, 1990: Observed enrichment of sulfate in precipitation from mid-latitude cyclonic storms. Preprints of Conf. on Cloud Physics, San Francisco, 23-27 July 1990, Am. Meteorol. Soc., Boston.

Chang, J.S., R.A. Brost, I.S.A. Isaksen, S. Madronich, P. Middleton, W.R. Stockwell, and C.J. Walcek, 1987: A three-dimensional Eulerian acid deposition model: Physical concepts and formulation. J. Geophys. Res., $\underline{92}$, D12, 14681-14700.

Chen, J-P, and D. Lamb, 1990: The role of precipitation microphysics in the selective filtration of air entering the upper troposphere. Preprints of Conf. on Cloud Physics, San Francisco, 23-27 July 1990, Am. Meteorol. Soc., Boston.

Dana, M.T., and W.R. Barchet, 1989: The MAP3S Precipitation Chemistry Network: Data and quality control summary for 1986 and 1987 . Report No. PNL $-6885 /$ UC -402 of PNL, Richland, WA.

Dana, M.T., and R.C. Easter, 1987: Statistical summary and analyses of event precipitation chemistry from the MAP3S Network, 1976-1983. Atmos. Environ., 21, 113-128.

de Pena, R.G., T.N. Carlson, J.F. Takacs, and J.O. Holian, 1984: Analysis of precipitation collected on a sequential basis. Atmos. Environ., 18 2665-2670.

de Pena, R.G., J.A. Pena, and V.C. Bowersox, 1980: Precipitation collectors intercomparison study. Penn State Report of subcontract No. 1416309 with the University of California.

de Pena, R.G., G.D. Rolph, J.F. Takacs, and J.O. Holian, 1986: Application of trajectory analysis to the assessment of local and long-range contributions to acidic deposition. Water, Air, and Soil Pollut., $\underline{30}, 885-896$.

de Pena, R.G., K.C. Walker, L. Lebowitz, and J.G. Micka, 1985: Wet deposition monitoring - Effect of sampling period. Atmos. Environ., $\underline{19}$, 151-156.

Heffter, J.L., 1983: Branching atmospheric trajectory (BAT) model. NOAA Technical Memorandum ERL ARL-121, 16 pp. (Available from NOAA Air Resources Lab, Rockville, MD).

Lamb, D., and J-P Chen, 1990: A modeling study of the effects of ice-phase microphysical processes on trace chemical removal efficiencies. Atmos. Res., $\underline{25}, 31-51$.

Lamb, D., D.F. Miller, N.F. Robinson, and A.W. Gertler, 1987: The importance of liquid water concentration in the atmospheric oxidation of $\mathrm{SO}_{2}$. Atmos. Environ., $\underline{21}$, 2333-2344. 
MacCracken, M.C., 1978: MAP3S: An investigation of atmospheric, energy related pollutants in the northeastern United States. Atmos. Environ., 12, 649-659.

MAP3S/RAINE, 1982: The MAP3S/RAINE precipitation chemistry network: Statistical overview for the period 1976-1980. Atmos. Environ., 16, 1603-1631.

Meszaros, E., and T. Szentimrei, 1985: On the wet removal of gaseous and particulate sulfur and nitrogen species from the atmosphere. J. Atmos. Chem., $\underline{2}, 405-413$.

Sweeney, J.K., and A.R. Olsen, 1987: Acid precipitation in North America: 1985 annual and seasonal data summaries from Acid Deposition System data base. EPA Report EPA/600/4-87/035, Nov. 1987, 451 pp.

Vet, R.J., A. Sirois, D. Lamb, and R. Artz, 1989: Intercomparison of precipitation chemistry data obtained using CAPMoN and NADP/NTN protocols. NOAA Technical Memorandum ERL ARL-174, $39 \mathrm{pp}$. (Available from NTIS, 5285 Port Royal Road, Springfield, VA 22161).

Watson, C.R., and A.R. Olsen, 1984: Acid Deposition System (ADS) for statistical reporting. System design and User's Code Manual. Document EPA-600-8-84, U.S. EPA, Research Triangle Park, NC.

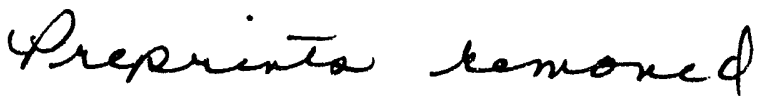



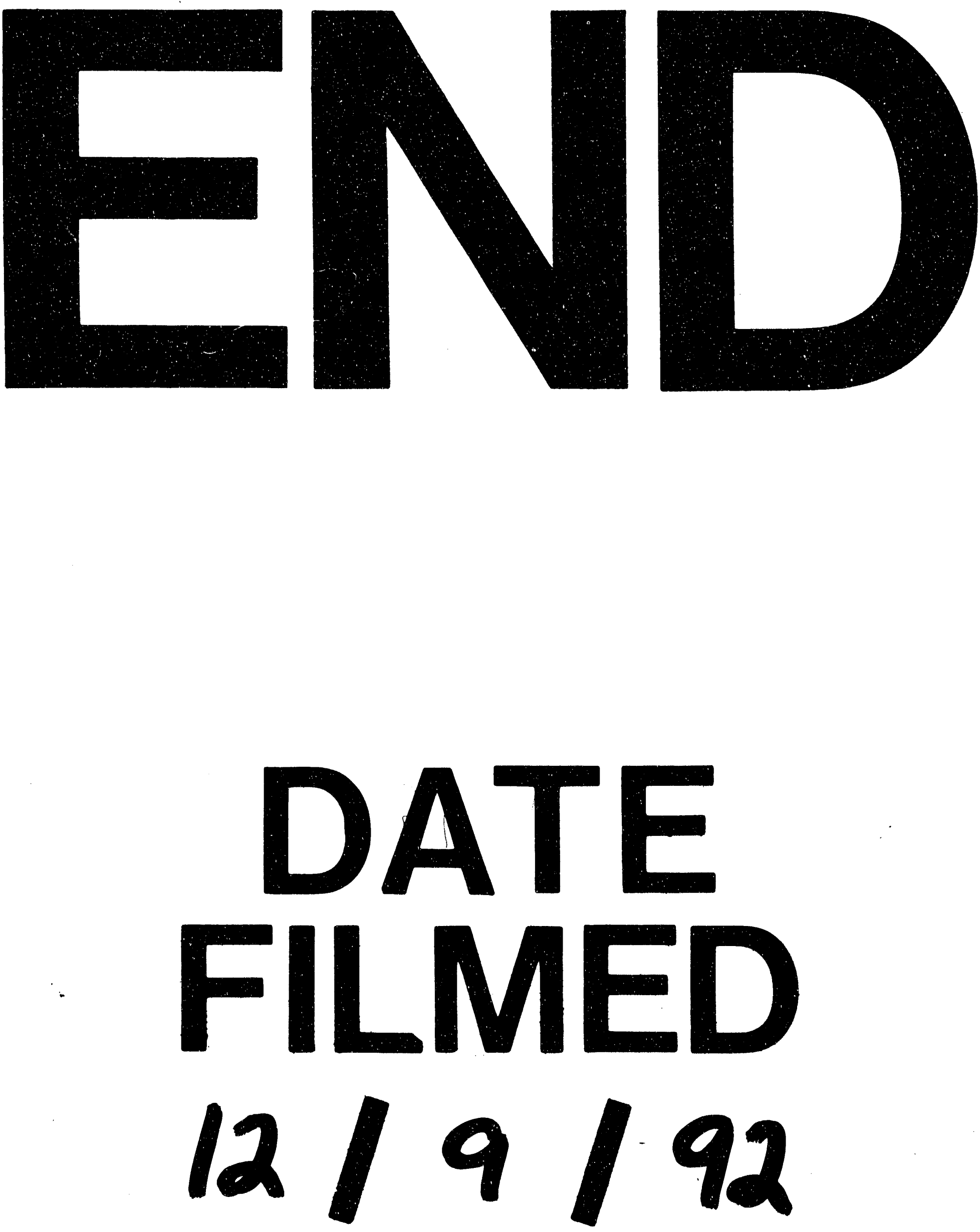

1 
